\title{
Nanomedicines for cancer therapy: state-of-the-art and limitations to pre-clinical studies that hinder future developments
}

\section{Charlene M. Dawidczyk ${ }^{1,2,3+}$, Luisa M. Russell ${ }^{1,2,3+}$ and Peter C. Searson ${ }^{1,2,3 *}$}

${ }^{1}$ Institute for Nanobiotechnology, Johns Hopkins University, Baltimore, MD, USA

2 Johns Hopkins Center of Cancer Nanotechnology Excellence, Johns Hopkins University, Baltimore, MD, USA

${ }^{3}$ Department of Materials Science and Engineering, Johns Hopkins University, Baltimore, MD, USA

\author{
Edited by: \\ João Conde, Massachusetts \\ Institute of Technology, USA \\ Reviewed by: \\ Yanli Zhao, Nanyang Technological \\ University, Singapore \\ Fernando Novio, Institut Catalá de \\ Nanociència i Nanotecnologia, Spain \\ *Correspondence: \\ Peter C. Searson, Johns Hopkins \\ University, 100 Croft Hall, 3400 \\ North Charles Street, Baltimore, MD \\ 21218, USA \\ e-mail: searson@jhu.edu \\ these authors have contributed \\ equally to this work.
}

The ability to efficiently deliver a drug or gene to a tumor site is dependent on a wide range of factors including circulation time, interactions with the mononuclear phagocyte system, extravasation from circulation at the tumor site, targeting strategy, release from the delivery vehicle, and uptake in cancer cells. Nanotechnology provides the possibility of creating delivery systems where the design constraints are decoupled, allowing new approaches for reducing the unwanted side effects of systemic delivery, increasing tumor accumulation, and improving efficacy. The physico-chemical properties of nanoparticle-based delivery platforms introduce additional complexity associated with pharmacokinetics, tumor accumulation, and biodistribution. To assess the impact of nanoparticle-based delivery systems, we first review the design strategies and pharmacokinetics of FDA-approved nanomedicines. Next we review nanomedicines under development, summarizing the range of nanoparticle platforms, strategies for targeting, and pharmacokinetics. We show how the lack of uniformity in preclinical trials prevents systematic comparison and hence limits advances in the field.

Keywords: drug delivery systems, nanoparticles, targeted therapy, pharmacokinetics, tumor accumulation

\section{INTRODUCTION}

Drug therapy often involves the use of small molecules such as alkylating agents (e.g., busulfan), anti-metabolites (e.g., gemcitabine), anti-microtubule agents (e.g., paclitaxel, vincristine), topoisomerase inhibitors (e.g., topotecan), and cytotoxic inhibitors (e.g., doxorubicin). These cytotoxic molecules kill highly proliferative cancer cells, but also other proliferative cells in bone marrow, the gastrointestinal (GI) tract, and hair follicles, leading to common side effects such as compromised immune system, inflammation and ulceration of the GI tract, and hair loss. Nanotechnology provides the possibility of creating delivery systems where the design constraints are decoupled, allowing new approaches for reducing the unwanted side effects of systemic delivery, increasing tumor accumulation, and improving efficacy.

The development of safe and efficient delivery systems is also important for advances in human gene therapy (Pack et al., 2005; Jones et al., 2013). A delivery system must transport a gene with high efficiency to target cells, with minimal toxicity and immune response. The main challenges for gene delivery are protecting the genetic material from degradation in circulation, avoiding degradation by enzymes in endosomes in the target cell, and escaping from endosomes to reach the nucleus or target compartment (Mintzer and Simanek, 2009; Zhang et al., 2012).

Key properties for drug and gene delivery systems are biocompatibility, stability in circulation, and increasing the fraction of the dose accumulating in the tumor. Drug toxicity can be reduced by encapsulating the free drug (e.g., liposomes) or by locally activating a pro-drug. Stability in circulation can be improved by developing strategies to minimize protein binding and evade the immune system. The efficiency of accumulation at a tumor site can be improved by active targeting of the delivery system or by increasing extravasation by the enhanced permeation and retention (EPR) effect.

The FDA-approved nanomedicines in clinical use have demonstrated the potential for increasing bioavailability, enhancing drug solubility, active targeting, and high drug loading (Dawidczyk et al., 2014). However, there remain many challenges in exploiting advances in nanotechnology and bioengineering to develop systems that will have significant impact on patient survival rates. The development of delivery systems remains largely empirical and the lack of standardization of pre-clinical studies is a barrier to establishing design rules for nanomedicines. While studies of complex systems with combined reporting/sensing functions along with drug or gene delivery may ultimately improve diagnosis and treatment, there are many fundamental issues that need to be addressed to establish the relationship between physico-chemical properties, pharmacokinetics, biodistribution, and survival rates.

Tumor uptake is modulated by the EPR effect (Jain and Stylianopoulos, 2010; Fang et al., 2011; Torchilin, 2011) and hence increasing the circulation time generally increases tumor accumulation. A common approach for increasing circulation time 
is to provide a surface coating of polyethylene glycol (PEG). Whilst PEG coating increases circulation time and hence can increase tumor accumulation, it also inhibits uptake by tumor cells (Barenholz, 2012). Furthermore, PEG coating slows but does not prevent adsorption of opsonins that promote uptake by macrophages of the liver and spleen. Targeting molecules such as immunoglobulin-G (IgG) antibodies are opsonins and hence promote clearance by the mononuclear phagocyte system (MPS) (Walkey and Chan, 2012). The conjugation of folate to liposomes significantly increases their uptake by tumor-associated macrophages (Turk et al., 2004).

\section{FDA-APPROVED NANOMEDICINES}

There are currently six FDA-approved nanomedicines (Table 1): brentuximab vedotin and Trastuzumab emtansine, Doxil, DaunoXome, Marqibo, and Abraxane (Dawidczyk et al., 2014). Brentuximab vedotin and Trastuzumab emtansine are antibody-drug conjugates (ADCs), conceptually one of the simplest nanomedicines with an anticancer drug conjugated to a targeting molecule. Brentuximab targets the protein CD30, a glycosylated phosphoprotein expressed by B cells, including B-cell lymphomas, some leukemias, and melanoma cancer stem cells (Mullard, 2013; Sassoon and Blanc, 2013; Sievers and Senter, 2013). Trastuzumab targets the human epidermal growth factor receptor 2 (HER2) overexpressed in HER2 positive breast cancer (Lu et al., 2012; Verma et al., 2012). Monomethyl auristan E (MMAE) (Brentuximab vedotin) and mertansine (Trastuzumab emtansine) are too toxic to be used alone and hence coupling to a targeting antibody reduces toxic side effects. Several drug molecules are conjugated to each antibody via a valine-citrulline cleavable linker (Brentuximab vedotin) or covalent linkage (Trastuzumab emtansine) that is enzymatically degraded in endosomes following uptake. The small number of FDA-approved ADCs highlights the difficulty in translating relatively simple nanomedicines to the clinic.

Doxil, DaunoXome, and Marqibo are liposomal nanomedicines. Doxil is a pegylated liposome about $100 \mathrm{~nm}$ in diameter and encapsulating about 10,000 doxorubicin molecules (Barenholz, 2012). Encapsulation minimizes side effects, such as cardiotoxicity, associated with high doses of free doxorubicin. The concentration of doxorubicin in the liposomes is greater than the solubility limit and hence most of the drug is in the solid phase (Barenholz, 2012). The incorporation of cholesterol increases the bilayer cohesiveness and reduces leakage. These features minimize osmotic effects and contribute to stability, with more than $98 \%$ of the circulating drug remaining inside liposomes (Lasic et al., 1992; Gabizon et al., 1994, 2003). The polyethylene glycol coating is designed to give a long circulation half time and thereby increase tumor accumulation by the EPR effect (Immordino et al., 2006; Vllasaliu et al., 2014). While the

Table 1 | Summary of FDA-approved nanomedicines.

\begin{tabular}{|c|c|c|c|c|c|c|}
\hline Platform & Class & Drug & $d(n m)$ & $\begin{array}{l}\text { Drug/carrier } \\
\text { ratio }\end{array}$ & Key design feature(s) & Problem addressed \\
\hline Brentuximab vedotin & ADC & Monomethyl auristan $\mathrm{E}$ & $\sim 10$ & $\leq 8$ & $\begin{array}{l}\text { Valine-citrulline linker } \\
\text { cleaved by cathepsin in } \\
\text { endosomes }\end{array}$ & $\begin{array}{l}\text { Monomethyl auristan } \mathrm{E} \\
\text { (MMAE) is too toxic to be } \\
\text { used alone }\end{array}$ \\
\hline Trastuzumab emtansine & ADC & Mertansine & $\sim 10$ & $\leq 8$ & $\begin{array}{l}\text { Non-cleavable linker; } \\
\text { release of drug by } \\
\text { proteolytic degradation of } \\
\text { antibody in endosomes }\end{array}$ & $\begin{array}{l}\text { Mertansine is too toxic to } \\
\text { be used alone }\end{array}$ \\
\hline Doxil & Liposome & Doxorubicin & 100 & $10,000-15,000$ & $\begin{array}{l}\text { Lipid encapsulation for } \\
\text { high drug/carrier ratio, } \\
\text { polyethylene glycol } \\
\text { coating to evade MPS, } \\
\text { crystallization of drug in } \\
\text { liposome minimizes } \\
\text { escape during circulation }\end{array}$ & $\begin{array}{l}\text { Drug toxicity and adverse } \\
\text { cardiac side effects }\end{array}$ \\
\hline DaunoXome & Liposome & Daunorubicin & 50 & $\sim 10,000$ & $\begin{array}{l}\text { No polyethylene glycol } \\
\text { coating, targeted by MPS } \\
\text { resulting in slow release } \\
\text { into circulation }\end{array}$ & $\begin{array}{l}\text { Drug toxicity and adverse } \\
\text { cardiac side effects }\end{array}$ \\
\hline Marqibo & Liposome & Vincristine & 100 & $\sim 10,000$ & $\begin{array}{l}\text { No polyethylene glycol } \\
\text { coating, targeted by MPS } \\
\text { resulting in slow release } \\
\text { into circulation }\end{array}$ & $\begin{array}{l}\text { Drug toxicity and adverse } \\
\text { side effects }\end{array}$ \\
\hline Abraxane & Protein carrier & Paclitaxel & 130 & $>10,000$ & $\begin{array}{l}\text { Non-specific binding of } \\
\text { paclitaxel to albumin }\end{array}$ & $\begin{array}{l}\text { Overcomes very low } \\
\text { solubility of paclitaxel }\end{array}$ \\
\hline
\end{tabular}


mechanisms of uptake and release are not known, evidence suggests that the liposomes are taken up by endocytosis (Seynhaeve et al., 2013).

DaunoXome (Gill et al., 1996; Bellott et al., 2001; Lowis et al., 2006) and Marqibo (Bedikian et al., 2011; Silverman and Deitcher, 2013) are liposomal formulations of daunorubicin and vincristine, respectively. In contrast to Doxil, the design strategy for DaunoXome and Marqibo is to promote uptake by the MPS, providing a reservoir from which the free drug can enter circulation, similar to a slow infusion. This is achieved by not including pegylated lipids in the liposomes (Gill et al., 1996; Bellott et al., 2001; Silverman and Deitcher, 2013). DaunoXome is about $50 \mathrm{~nm}$ in diameter (Gill et al., 1996), and Marqibo is about $100 \mathrm{~nm}$ in diameter (Silverman and Deitcher, 2013).

Abraxane, or nab-paclitaxel (nanoparticle albumin bound), is lyophilized human serum albumin non-specifically bound to paclitaxel (Miele et al., 2009). Paclitaxel has very low solubility and is administered with the toxic non-ionic solvent Cremophor, which can lead to a wide range of allergic reactions. On injection, Abraxane particles dissociate into smaller albuminpaclitaxel complexes or unbound paclitaxel (Yardley, 2013). Since albumin is abundant in circulation, Abraxane provides a reservoir of a very low solubility drug in a non-toxic platform. The particles are about $130 \mathrm{~nm}$ in diameter and contain about 10,000 paclitaxel molecules (Miele et al., 2009).

The pharmacokinetics of these nanomedicines reflects their design (Table 2). Brentuximab vedotin and Trastuzumab emtansine both have moderate areas under the curve (AUCs), relatively low clearance, and long elimination half-times of 3-4 days (Younes et al., 2010; Lorusso et al., 2011; Girish et al., 2012; Lu et al., 2012; Bradley et al., 2013). Doxil has high AUC, low clearance rate, small distribution volume, and a long elimination half-time (Barenholz, 2012). These features are largely due to the polyethylene glycol coating that provides extended evasion of the MPS and minimizes distribution into peripheral tissues
(Gabizon et al., 1994; Hubert et al., 2000; Lyass et al., 2000; Hong and Tseng, 2001; Hamilton et al., 2002). DaunoXome (Gill et al., 1996; Bellott et al., 2001; Lowis et al., 2006) and Marqibo (Bedikian et al., 2011; Silverman and Deitcher, 2013) have clearance rates about an order of magnitude larger than for the ADCs and Doxil, low distribution volumes, and short elimination half-times on the order of $10 \mathrm{~h}$. The larger AUC associated with DaunoXome is related to the larger dose range compared to Marqibo. Abraxane has a fast clearance rate, about two orders of magnitudes larger than DaunoXome and Marqibo, large distribution volume, and elimination half-time similar to DaunoXome and Marqibo (Sparreboom et al., 2005; Ando et al., 2012). The pharmacokinetics for Abraxane are similar to free paclitaxel and the other free drugs: low AUC, high clearance rate, high distribution volume, and short elimination half-time.

Overall it is evident that antibody drug conjugates or liposomes with a pegylated surface have long elimination halftimes, typically of 3-4 days. Increasing elimination half-times is expected to increase tumor accumulation via the EPR effect. However, increased tumor accumulation does not necessarily imply improved efficacy since processes such as transport, uptake, drug release, and delivery to the appropriate cellular compartment are all downstream of extravasation by the EPR effect.

\section{NANOPARTICLE PLATFORMS, TARGETING MOIETIES NANOPARTICLE PLATFORMS}

The development of a broad range of nanoparticle platforms with the ability to tune size, composition, and functionality has provided a significant resource for nanomedicine (Table 3 ) (Niemeyer, 2001; Duncan, 2006; Cho et al., 2008; Greco and Vicent, 2009; Yu et al., 2013). Nanoparticle platforms can be broadly categorized as organic, inorganic, and hybrid.

Organic nanoparticles have been widely explored for decades, yielding a large variety of materials, formulations, imaging modalities, cargo, and targets for cancer therapy.

Table 2 | Summary of pharmacokinetics for FDA-approved nanomedicines and corresponding free drugs from human clinical trials.

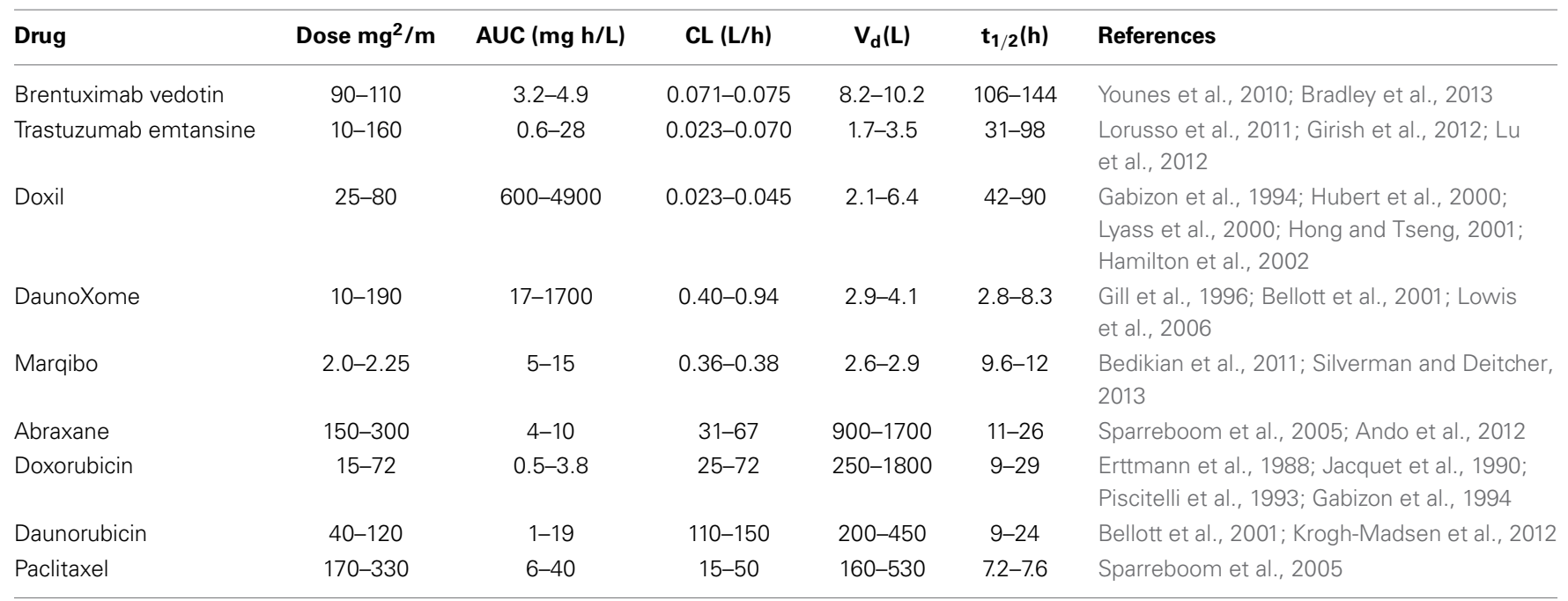

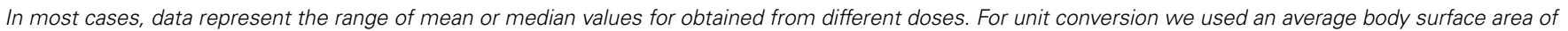
$1.7 \mathrm{~m}^{2}$, an average body weight of $60 \mathrm{~kg}$, and a blood volume of $5 \mathrm{~L}$. 
Table 3 | Summary of nanoparticle platforms for nanomedicine.

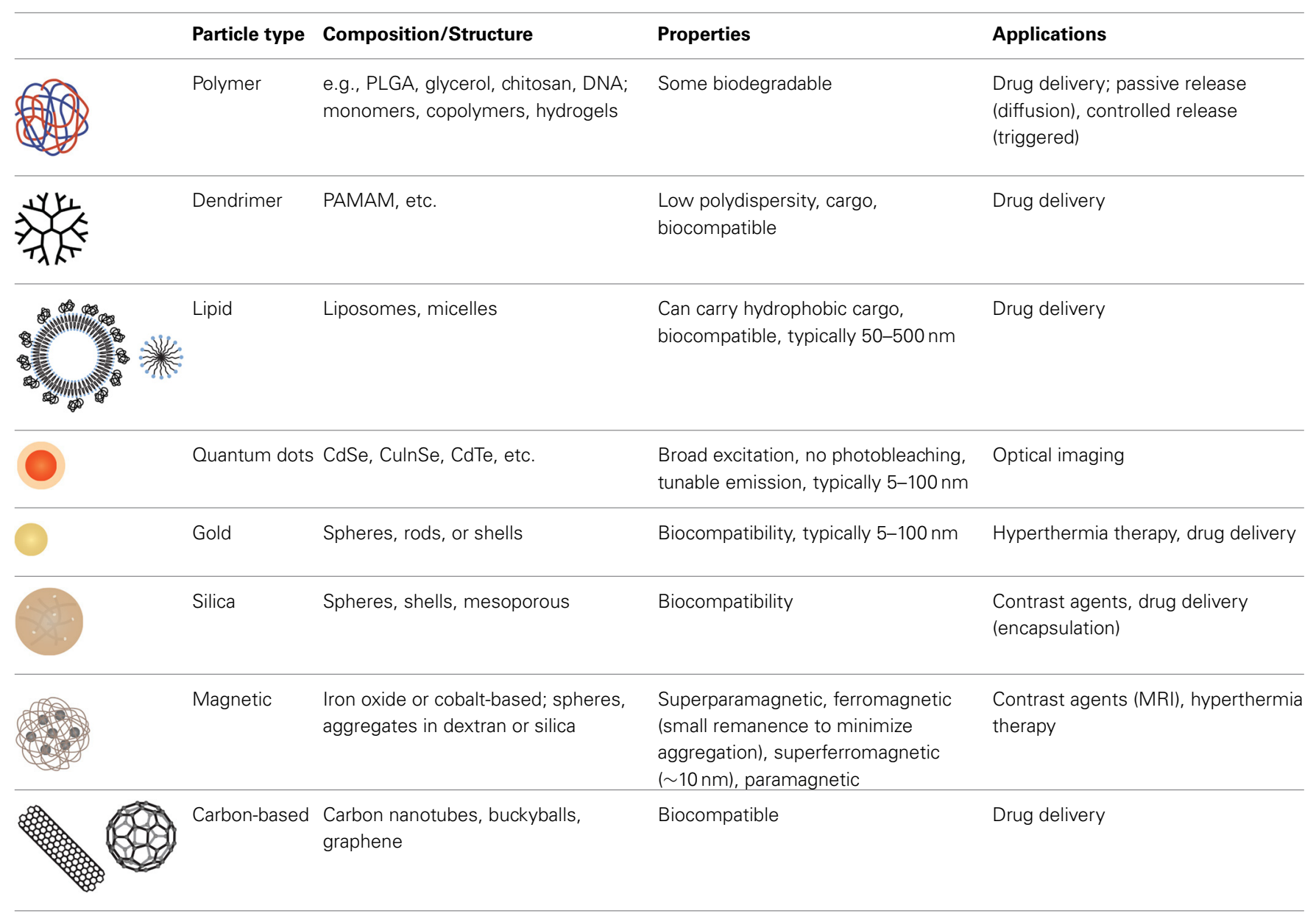

Organic polymer systems include synthetic polymers [e.g., polyethyleneimine (PEI), polyethylene glycol] (Knop et al., 2010; Nicolas et al., 2013), synthetic hydrogels (e.g., polyacrylamide) (Ando et al., 2012; Liechty and Peppas, 2012), natural polymers (e.g., chitosan, hyaluronic acid, alginate, gelatin) (Ando et al., 2012) and hydrolytically or enzymatically degradable polymers (e.g., collagen, polylactic acid, polycaprolactone) (Balogh et al., 2007). Combinations of components and/or monomer units and incorporation of other building blocks such as DNA contribute to the flexibility of polymer-based nanoparticle platforms. These systems can be passively loaded with a cargo, or a cargo can be incorporated to allow triggered release (Davis et al., 2008). Particles such as block copolymers, liposomes, and dendrimers can provide a reservoir for large amounts of cargo. Block copolymers combine the attributes of two or more monomer units allowing further functionality (Duncan, 2006; Greco and Vicent, 2009). Lipid-based nanoparticles include micelles, liposomes, or water oil emulsions. Dendrimers are hyperbranched synthetic polymers for which biodistribution, size, and multifunctionality can be tuned with a very low degree of polydispersity (Cho et al., 2008). Proteins (e.g., albumin) (Fuchs and Coester, 2010) and viruses (Steinmetz, 2010) have also been extensively studied for drug and gene delivery.
Inorganic nanoparticles provide advantages in function and properties not possible with organic nanoparticle platforms, although this is often at the expense of biocompatibility. Examples of materials include semiconductors (quantum dots) (Gao et al., 2004; Medintz et al., 2005; Michalet et al., 2005; Park et al., 2011; Chen et al., 2012a; Petryayeva et al., 2013), silica (Vanblaaderen and Vrij, 1992; Giri et al., 2005, 2007; Burns et al., 2006), gold (Boisselier and Astruc, 2009; Arvizo et al., 2010), magnetic materials (Arruebo et al., 2007; Banerjee et al., 2010; Haun et al., 2010), and carbon-based materials (Prato et al., 2008; Jain, 2012). Semiconductor nanoparticles, or quantum dots, have a narrow and tunable emission spectrum, a broad excitation spectrum, and do not photobleach. These characteristics are attractive for optical imaging, however, many quantum dots are synthesized from heavy metal elements and hence toxicity is a concern. Silicon dioxide (silica), the most widely used oxide, is a versatile material that is relatively inert. Silica can be used to encapsulate other materials or cargoes and the surface can be conjugated using silane chemistry. Silica can be synthesized with nanometer scale pores (mesoporous silica) that can be used to hold other cargoes. Of the metallic materials, gold is widely used for biological applications as it is easy to synthesize, can be functionalized using thiol chemistry, and is relatively inert. Many of the noble metals absorb 
electromagnetic radiation in the visible range of the spectrum (plasmon absorbance), and have been explored for hyperthermia therapy. Gold nanoparticles conjugated with PEG and tumor necrosis factor alpha ( $\mathrm{TNF} \alpha$ are being developed for targeted cancer therapy (Libutti et al., 2010).

Ferromagnetic materials, such as iron oxide (magnetite, $\mathrm{Fe}_{3} \mathrm{O}_{4}$ ), iron, cobalt, and nickel offer an additional degree of freedom in the synthesis of nanoparticles for nanomedicine (Arruebo et al., 2007). Very small ferromagnetic nanoparticles (typically $<10 \mathrm{~nm}$ ) have no intrinsic magnetization in the absence of a magnetic field, and hence do not aggregate in colloidal suspension. These superparamagnetic nanoparticles can be manipulated in an external field providing a simple method for spatial manipulation and washing. Magnetic nanoparticles, such as superparamagnetic iron oxide (SPIO) nanoparticles have been used for magnetic resonance imaging (MRI) and hyperthermia therapy (Yu et al., 2013).

Carbon-based nanoparticles have exploited the small size and unique properties of buckyballs, carbon nanotubes, and grapheme (Yu et al., 2013). Combinations of organic and inorganic materials, taking advantage of specific materials and structures have also been widely explored in multifunctional nanoparticle platforms.

Hybrid nanoparticles with organic and inorganic components or associated combinations of inorganic nanostructures provide further opportunities for introducing multiple functionalities. These systems can exploit the biocompatibility of organic nanoparticles, while still retaining the stability and function of inorganic nanoparticles. Inorganic nanoparticle conjugates allow for multimodal imaging and theranostic applications. Examples include constructs such as liposomes filled with magnetic nanoparticles (Sailor and Park, 2012), coordination polymer nanoparticles (Novio et al., 2013), and metal-organic frameworks (Horcajada et al., 2012).

\section{TARGETING MOIETIES (ANTIBODIES, APTAMERS, SMALL MOLECULES,}

\section{ETC.}

Active targeting of a nanoparticle is a way to minimize uptake in normal tissue and increase accumulation in a tumor. Strategies for active targeting of tumors usually involve targeting surface membrane proteins that are upregulated in cancer cells (Huynh et al., 2010; Hanahan and Weinberg, 2011). While this strategy is widely used, tumor cell populations are extremely heterogeneous and expression levels can vary significantly. Targeting molecules are typically antibodies (Dill et al., 1994; Arruebo et al., 2009; Chames et al., 2009), antibody fragments (Holliger and Hudson, 2005), aptamers (Keefe et al., 2010; Hu and Zhang, 2013), or small molecules (Figure 1).

Accumulation of a delivery system at a tumor site by the EPR effect is dependent in part on the concentration in the circulation. Processes such as clearance by the MPS or uptake in normal tissue decrease the concentration in circulation and hence decrease the accumulation in the tumor. Active targeting can provide an additional sink for a nanoparticle platform since expression of target molecules is usually differential in that the target is highly expressed in tumor cells but expressed at low levels in other cell types in the vascular system. Since the surface area of the

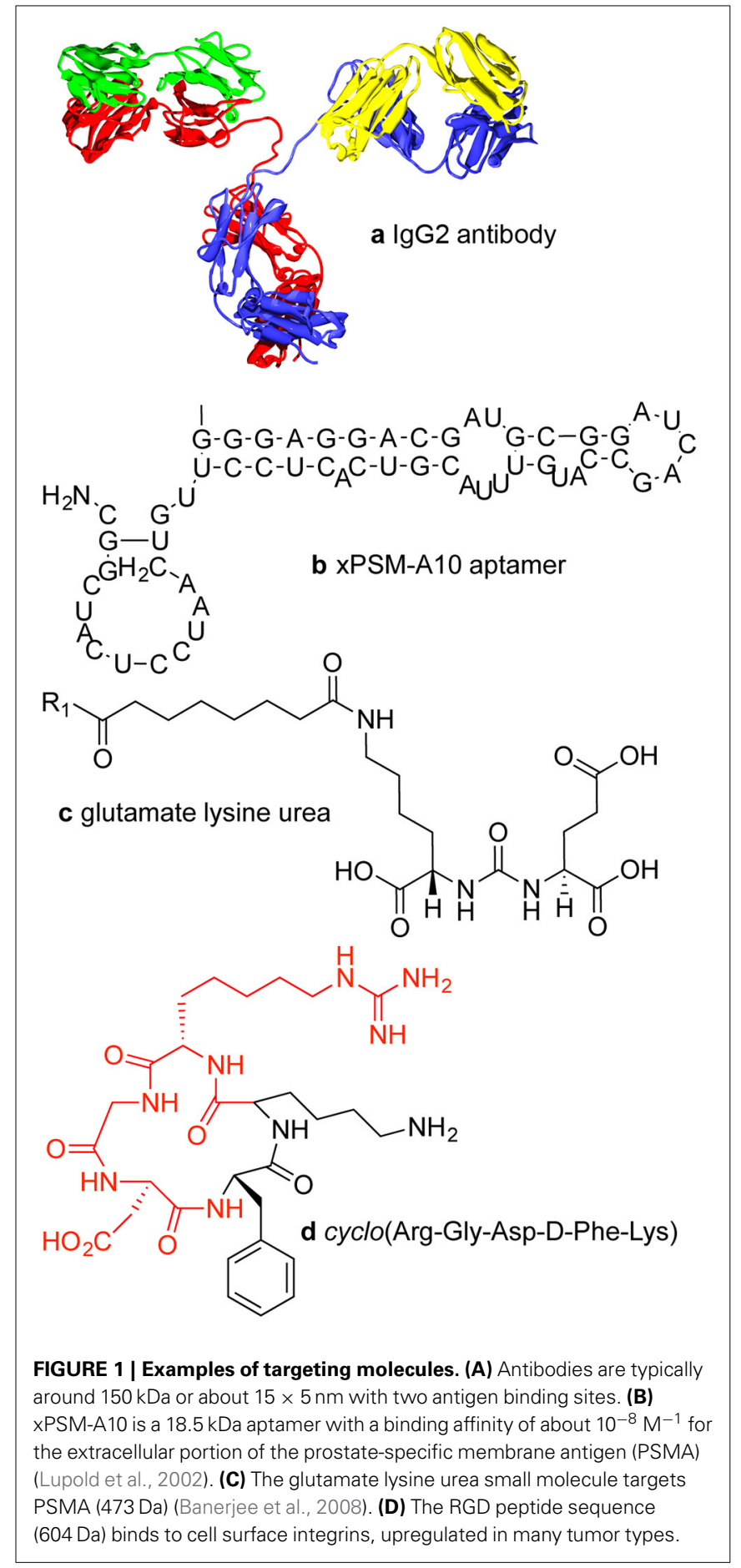

vasculature is much larger than the tumor, active binding in normal tissue can be significant, even for targets that are expressed at relatively low levels (Jain, 2005). Furthermore, targeting moieties may themselves be targets for receptors on phagocytic cells, as described above.

\section{Antibodies}

Monoclonal IgG antibodies (mAbs) are widely used for protein recognition and targeting since they have two epitope binding 
sites, high selectivity, and high binding affinity (Chames et al., 2009). Antibodies are the largest of the targeting ligands, approximately $150 \mathrm{kDa}$ or about $15 \mathrm{~nm}$ long and about $5 \mathrm{~nm}$ in diameter. The binding (dissociation) constants for antibody-antigen interactions vary over a wide range from $10^{-6}$ to $10^{-9} \mathrm{M}$, but can be as high as $10^{-12} \mathrm{M}$ for high affinity antibodies (Dill et al., 1994). For targeting applications, the Fc region of the antibody can be a disadvantage if it is accessible to $\mathrm{Fc}$ receptors on macrophages, which can lead to increased accumulation in the liver and spleen (Allen, 2002).

\section{Antibody fragments}

Antigen binding sites represent only a small part of the overall size of antibodies. $\mathrm{F}\left(\mathrm{ab}^{\prime}\right)_{2}$ fragments retain both antigen binding sites of the antibody coupled by disulfide linkages. Cleavage of the disulfide bond under reducing conditions yields two Fab' fragments with sulfhydryl groups that can be used for coupling to the targeting platform. Single chain variable fragments maintain only the variable regions (variable light chain and variable heavy chain) of one arm of an antibody.

\begin{abstract}
Aptamers
Aptamers are folded single strand oligonucleotides, 25-100 nucleotides in length $(8-25 \mathrm{kDa})$ that bind to molecular targets (Tuerk and Gold, 1990; Keefe et al., 2010). High throughput screening methods can be used for rapid selection of aptamers for specific targets (Bunka and Stockley, 2006). Macugen, approved for use in the treatment of macular degeneration in 2004, is currently the only FDA approved aptamer (Adamis et al., 2006).
\end{abstract}

\section{Small molecules}

Small molecules for targeting include peptides, growth factors, carbohydrates, ureas, and receptor ligands (Weissleder et al., 2005). Specific examples include folic acid, transferrin, and the RGD peptide sequence. Folic acid (441 Da) is recognized by the folic acid receptor and is expressed in normal epithelial cells but is overexpressed in many cancer types, especially ovarian, brain, and lung cancers (Kamen and Smith, 2004; Hilgenbrink and Low, 2005; Parker et al., 2005; Chames et al., 2009; Muller and Schibli, 2013; Naumann et al., 2013). Folic acid is essential for amino acid synthesis and hence for cell survival and proliferation, and has a high affinity $\left(K_{d}<10^{-9} \mathrm{M}\right)$ (Hartmann et al., 2007). Transferrin is a chelating protein that regulates the supply of iron into cells via receptor-mediated endocytosis (Kresse et al., 1998). The transferrin receptor is expressed at low levels in most normal tissues but is overexpressed in many tumor types (Daniels et al., 2012). The RGD (Arg-GlyAsp) peptide is a target for integrins (e.g., $\alpha_{v} \beta_{3}$ ) on the cell surface (Ruoslahti, 1996; Hynes, 2002). RGD is a component of the extracellular matrix protein fibronectin and promotes cell adhesion and regulates cell migration, growth, and proliferation (Ruoslahti, 1996; Hynes, 2002). A cyclic peptide containing the RGD sequence is widely used for targeting to integrins (Haubner et al., 1996). The upregulation of integrins is promoted by angiogenic factors in several cancer types (Dechantsreiter et al., 1999; Hosotani et al., 2002; Furger et al., 2003; Sheldrake and Patterson, 2009).

\section{TUMOR ACCUMULATION AND TARGETING EFFICIENCY}

In preclinical studies the efficacy of a drug is often determined from the time dependence of tumor size or from the fraction of animals that survive after a candidate therapy. These parameters are particularly useful in assessing the potential therapeutic benefit of a new delivery system but integrate many factors. An additional parameter that is important in assessing the potential efficacy of delivery systems is the tumor accumulation or targeting efficiency - the fraction of an intravenously administered dose that accumulates in a tumor (\%ID). Despite the importance of this parameter, very few measurements are reported in the literature.

We have reviewed 40 pre-clinical studies of delivery systems employing passive targeting (Supplementary Table S1), and 34 pre-clinical studies employing active targeting (Supplementary Table S2). Only studies reporting quantitative results of tumor accumulation were selected. Analysis of these pre-clinical studies highlights the need for guidelines to improve the overall impact of research in this field. Despite the importance of pharmacokinetics and tumor accumulation in assessing the efficiency of delivery systems, very few preclinical studies report quantitative results that can be used to develop design rules for nanomedicines.

\section{PASSIVE TARGETING}

Delivery systems used in pre-clinical studies exploiting passive targeting include liposomes (Harrington et al., 2000; Wang et al., 2006; Soundararajan et al., 2009; Zheng et al., 2009; Huang et al., 2011; Chen et al., 2012a; Coimbra et al., 2012; Hsu et al., 2012; Mahakian et al., 2014) (Kheirolomoom et al., 2010), micelles (Yokoyama et al., 1999; Le Garrec et al., 2002; Kawano et al., 2006; Reddy et al., 2006; Rijcken et al., 2007; Kim et al., 2008; Hoang et al., 2009; Shiraishi et al., 2009; Blanco et al., 2010; Sumitani et al., 2011; Wang and Gartel, 2011; Zhao et al., 2012; Miller et al., 2013; Zhu et al., 2013), gold nanoparticles (Hainfeld et al., 2006; Von Maltzahn et al., 2009; Puvanakrishnan et al., 2012), iron oxide nanoparticles (Ujiie et al., 2011), silica nanoparticles (Chen et al., 2012b; Di Pasqua et al., 2012), carbon-based nanostructures (Liu et al., 2011; Robinson et al., 2012; Rong et al., 2014), quantum dots (Sun et al., 2014), and hybrid nanomaterials (Balogh et al., 2007; Tinkov et al., 2010; Yang et al., 2012) (Paraskar et al., 2012) (Ohno et al., 2013) (Supplementary Table S1).

Of the 40 pre-clinical studies, only a few (4/40) reported tumor accumulation as $\% \mathrm{ID}$, while the remainder reported normalized accumulation as $\% \mathrm{ID} / \mathrm{g}$ or $\% \mathrm{ID} / \mathrm{cc}$. The tumor accumulation varies over a wide range from 0.1 to $35 \% \mathrm{ID} / \mathrm{g}$ at $24 \mathrm{~h}$ postinjection. Passive delivery systems are generally pegylated and have sizes in the range from 2 to $200 \mathrm{~nm}$. However, there are no clear trends in terms of identifying physico-chemical parameters that influence the pharmacokinetics or tumor accumulation. Although pegylation is generally assumed to increase circulation time and hence increase tumor accumulation, there is no consistent difference in tumor accumulation between pegylated and non-pegylated delivery systems.

Similarly, there is no obvious dependence on the size or shape of the delivery system. For example, the tumor accumulation of pegylated liposomes around $100 \mathrm{~nm}$ in diameter in three 
studies varied from 0.4 to $11 \% \mathrm{ID} / \mathrm{g}$ (Soundararajan et al., 2009; Kheirolomoom et al., 2010; Hsu et al., 2012). The large variation is likely due to the differences in xenograft cell line, tumor size, and dose. Similarly, tumor accumulation in two pre-clinical studies of $30 \mathrm{~nm}$ diameter micelles with different polymer formulations were 1.5\%ID/g (Yokoyama et al., 1999) and 9.5\%ID/g (Blanco et al., 2010). These two studies used different models (orthotopic vs. xenograft), tumor cell line (A549 vs. C26), tumor size $\left(200\right.$ vs. $\left.100 \mathrm{~mm}^{3}\right)$, and injected dose $(30-50 \mathrm{mg} / \mathrm{kg}$ vs. $10 \mathrm{mg} / \mathrm{kg}$ ). These differences in experimental design limit the ability to compare the two different micelle formulations. These examples highlight the difficulty in comparing pre-clinical trials due to the variability in experimental design.

\section{ACTIVE TARGETING}

Targeted delivery systems used in quantitative pre-clinical studies include silica (Benezra et al., 2011; Tang et al., 2012; Chen et al., 2013), gold (Melancon et al., 2008; Lu et al., 2009, 2010; Chanda et al., 2010; Choi et al., 2010; Morales-Avila et al., 2011; Chattopadhyay et al., 2012), liposomes (Iyer et al., 2011; Helbok et al., 2012; Petersen et al., 2012), micelles (Hu et al., 2008; Penate Medina et al., 2011; Zhang et al., 2011b; Fonge et al., 2012; Helbok et al., 2012) (Rossin et al., 2005; Khemtong et al., 2009; Zhan et al., 2010; Poon et al., 2011; Zhang et al., 2011a; Xiao et al., 2012), iron oxide (Natarajan et al., 2008; Kumar et al., 2010; Yang et al., 2011), graphene (Hong et al., 2012; Cornelissen et al., 2013; Shi et al., 2013), gadolinium (Oyewumi et al., 2004), polymer nanocarriers (Kunjachan et al., 2014), nanoemulsions (Ohguchi et al., 2008), quantum dots (Gao et al., 2010), and hybrid (Cheng et al., 2014) (Supplementary Table S2). Similar to passive targeting, few studies $(3 / 34)$ report \%ID rather than \%ID/g. The most common targeting ligands are antibody based (9/34 studies), the RGD peptide sequence (10/34), and folate (5/34). Targeting efficiencies obtained using RGD peptides, folate, antibodies, and antibody fragments are typically between 1 and 15\%ID/g (Supplementary Table S2).

Assessing the efficiency of a targeting ligand in increasing tumor accumulation is complicated by the different control experiments used in these studies. The contribution of passive targeting was assessed by measuring tumor accumulation of the delivery system without attachment of the targeting ligand (20/34), with attachment of a non-specific ligand (2/34), pre-injection with a blocking molecule or treatment (10/34), or with a xenograft formed from a cell line that did not express the target molecule (2/34). Several studies (4/34) did not report a control experiment. Each control experiment has advantages and disadvantages. For example, removing a targeting ligand from a delivery system may alter the physico-chemical properties and hence change the pharmacokinetics. As described in more detail below, xenografts formed from different cell lines may have significantly different vascularization and hence the rate of extravasation to the tumor site by the EPR effect may be significantly different. Pre-injection with a blocking molecule may not completely prevent binding to the target molecule or may reduce binding in normal tissue. To account for these potential complications, a few studies (3/34) used multiple controls.
Of the 30 pre-clinical studies that reported control experiments, 33\% (10/30) showed less than a two-fold increase in targeting compared to the control, and 50\% (15/30) showed an increase in tumor accumulation of more than $2 \% \mathrm{ID} / \mathrm{g}$ with the targeting ligand. For example, a tumor accumulation of $9 \%$ ID was reported for SPIONS with anti-ChL6 2 days post-injection compared to $1 \%$ without the targeting antibody (Natarajan et al., 2008). A tumor accumulation of $7 \pm 1 \%$ ID was reported for gadolinium nanoparticles with a folate targeting ligand, and $9 \pm$ $4 \%$ ID in the control with no targeting ligand (Oyewumi et al., 2004). While active targeting of a delivery system to a tumor site has the potential to reduce unwanted side effects, these studies highlight the difficulties in assessing targeting efficiency due to the large differences in experimental design and the range of controls used to assess the contribution of passive targeting.

\section{TUMOR ACCUMULATION}

In general, the uptake of a delivery system in a tumor tends to increase post-injection but then decreases at longer times (Supplementary Table S1 and S2). For example, tumor accumulation of radiolabeled liposomes increased to $11.3 \% \mathrm{ID} / \mathrm{g}$ over the first $24 \mathrm{~h}$, then decreased to $6.1 \% \mathrm{ID} / \mathrm{g}$ after $72 \mathrm{~h}$ (Hsu et al., 2012). Tumor accumulation of self-activating quantum dots increased to $13 \% \mathrm{ID} / \mathrm{g}$ over the first $24 \mathrm{~h}$, but decreased to $11 \% \mathrm{ID} / \mathrm{g}$ after $42 \mathrm{~h}$ (Sun et al., 2014). Similarly, tumor accumulation of pegylated micelles with a gelatinase binding peptide was reported to increase to almost $18 \% \mathrm{ID} / \mathrm{g}$ over the first $6 \mathrm{~h}$, but decreased to $2 \%$ ID/g after $24 \mathrm{~h}$ (Penate Medina et al., 2011). Tumor accumulation of gold nanoparticles with the RGD peptide increased to $3.65 \%$ ID/g over the first hour followed by a decrease by almost half to $1.94 \%$ ID/g 24 h post-injection (Morales-Avila et al., 2011). The details of the time dependence of tumor accumulation are important in understanding the pharmacokinetics, the EPR effect, and the limitations to accumulating a drug at the tumor site. In many studies, an insufficient number of time points precludes detailed analysis of pharmacokinetics and tumor accumulation.

The cell line used in forming a xenograft can have significant influence on tumor accumulation and efficacy. In the 74 quantitative pre-clinical trials reviewed here, 35 different cell types were used to form xenografts. The most common cell lines were the 4T1 murine breast cancer cell line (10/71) and the C26 colon carcinoma cell line (10/71), both of which form highly vascularized tumors. Tumor accumulation of micelles with the RGD peptide was $6 \% \mathrm{ID} / \mathrm{g}$ in a mouse model with a C26 xenograft and $3 \% \mathrm{ID} / \mathrm{g}$ with a less leaky BxPC3 xenograft (Kunjachan et al., 2014), highlighting the need for standardization of cell lines.

Tumor size can have a significant influence on tumor accumulation. For example, a study using radiolabeled liposomes compared targeting efficiency among tumors of different sizes using the KB cell line (Harrington et al., 2000). The tumor accumulation for small tumors $(\leq 0.1 \mathrm{~g})$ was around $15 \% \mathrm{ID} / \mathrm{g}$, whereas for larger tumors $(\geq 1 \mathrm{~g})$ was only $3 \% \mathrm{ID} / \mathrm{g}$.

\section{GUIDELINES FOR PRE-CLINICAL STUDIES OF DELIVERY SYSTEMS}

While the physico-chemical properties of delivery systems are expected to exert a significant influence on pharmacokinetics, 
tumor accumulation, and biodistribution, there are numerous problems in comparing pre-clinical studies. In particular, differences in cell line and tumor size, dose, lack of good pharmacokinetics data, and differences in reporting make meta-analysis extremely difficult and are a limitation to progress in the field (Table 4). Similarly, physico-chemical properties of the delivery system such as size, surface properties (i.e., pegylation), zeta potential, targeting ligand density, and stability in blood or serum at physiological temperature are not uniformly reported.

For example, results are usually reported as percent of initial administered dose per gram of tumor $(\% \mathrm{ID} / \mathrm{g})$, which is only useful if the tumor mass is also reported. For example, a tumor accumulation of $10 \% \mathrm{ID} / \mathrm{g}$ is $10 \%$ of the initial dose for a $1 \mathrm{~g}$

Table 4 | Summary of limitations to pre-clinical studies of nanomedicines that hinder broad assessment of design rules.

\begin{tabular}{ll}
\hline Problem & Solution \\
\hline $\begin{array}{ll}\text { Total tumor accumulation (\% ID) is } \\
\text { not always reported }\end{array}$ & $\begin{array}{l}\text { Report tumor accumulation as \% ID } \\
\text { (and \% ID/g) }\end{array}$ \\
$\begin{array}{l}\text { Inconsistent reporting of tumor } \\
\text { size/weight }\end{array}$ & Report tumor size/weight
\end{tabular}

Inconsistent reporting of dose

Report dose as total number of nanoparticles injected

Along with other parameters such as drug loading, drug concentration (and/or drug amount), and activity of dose (gamma counter)

Inconsistent reporting of physico-chemical properties

umor accumulation reported at different time points
Report standard physico-chemical properties (e.g., size, zeta potential, surface coating, stability under physiological conditions)

Report tumor accumulation at standard time points (e.g., 1 and $24 \mathrm{~h}$ post-injection). Detailed pharmacokinetics (concentration in blood and tumor) at multiple time points is preferred
Variation in tumor characteristics (type, size, vascularization, etc.)

Variation in controls used in active targeting

Standardize tumor type and size (e.g., C26 or 4T1; $1 \mathrm{~cm}$ diameter) More difficult for active targeting depending on target molecule

Report control studies for delivery system with no targeting ligand and any differences in physico-chemical properties. Report other control studies as necessary

Variation in animal models (mouse, rat, etc.) and differences in drug Use mouse xenograft model for initial pre-clinical studies

concentration compared to humans

Different detection methods used to assess tumor accumulation
Perform validation using other method(s) tumor but $1 \%$ of the initial dose for a $0.1 \mathrm{~g}$ tumor. These differences are significant in terms of the efficiency of delivery and minimizing unwanted side effects in normal tissue. In some cases tumor characteristics such as tumor diameter or approximate tumor volume are reported, however, these parameters can only be used to estimate the absolute percentage of the initial dose.

Mouse models are widely used for research studies of disease progression and the development of new therapies (Frese and Tuveson, 2007). Rat and rabbit models are also commonly used for pre-clinical studies. Standard tumor models include subcutaneous xenografts of human cell lines or explants, orthotopic xenografts, and genetically engineered mouse models (Frese and Tuveson, 2007; Chen et al., 2012a). While these models are invaluable for pre-clinical studies, differences in physiology can lead to differences in circulation and tumor accumulation compared to humans (Steichen et al., 2012).

Xenografts represent a relatively straightforward model to study the pharmacokinetics, tumor accumulation, and biodistribution of a nanomedicine, however, tumor characteristics vary considerably with cell line and size (Harrington et al., 2000; Jain and Stylianopoulos, 2010). The density and vascularization of tumors of similar size can also vary significantly. Highly invasive cell lines often form more highly vascularized tumors, for example xenografts of colon cancer cell lines have vasculature that is much more leaky than pancreatic cancer cell lines. Therefore, tumor uptake by the EPR effect is expected to be strongly dependent on the cell line used. Establishing a standard cell line and tumor size for xenografts would greatly enhance comparison of pre-clinical trials of delivery systems (Table 4). While this is feasible for passive delivery systems, active targeting often requires the use of specific cell lines that overexpress a particular biomarker.

Tumor accumulation is usually measured using a gamma counter, positron emission tomography (PET), or inductively coupled plasma mass spectroscopy (ICP-MS). The methods using a gamma counter or PET require that a suitable radiolabel is conjugated to the drug delivery platform. With a gamma counter, the radioactivity of the resected tumor is measured and compared to the radioactivity of the dose. To determine the tumor accumulation from PET scans, reconstructed 3D regions of interest are drawn around the tumor. The activity per unit mass can then be determined after correcting for decay and tissue density. An alternative to using a radiolabel to measure the tumor accumulation is to use ICP-MS to determine the amount of one or more elemental components in the delivery system and to compare to the initial dose. However, this method requires a component of the delivery system to be distinguishable from biological matter. In most pre-clinical studies only one of the methods is used to determine pharmacokinetics and tumor accumulation and hence there is no independent verification.

Tumor accumulation is expected to be dependent on the dose and time post-injection, and hence time-course studies at different doses are important for full characterization. In many cases, tumor accumulation is determined only at one or two time points therefore limiting analysis of the pharmacokinetics which is crucial for developing design rules. 


\section{SUMMARY}

Nanoparticle-based delivery systems provide new opportunities to overcome the limitations associated with traditional drug therapy and to achieve both therapeutic and diagnostic functions in the same platform. The efficiency of drug or gene delivery to a tumor site is dependent on the physico-chemical properties of the delivery platform and a range of physiologically imposed design constraints including clearance by the mononuclear phagocyte system and extravasation from circulation at the tumor site by the enhanced permeability and retention effect.

The lack of uniformity in pre-clinical trials of nanoparticlebased delivery systems has prevented systematic comparison of these studies and has been an impediment to developing design rules for new systems or specific applications. Of the large number of pre-clinical trials, surprisingly few report quantitative data on parameters that would be useful in developing design rules for nanomedicines. The poor experimental design and variability of experimental conditions also contribute to slow development of the field and the lack of clinical impact. We highlight some of the problems with pre-clinical trials nanoparticle-based delivery systems and suggest some solutions to increase the impact of individual studies.

\section{SUPPLEMENTARY MATERIAL}

The Supplementary Material for this article can be found online at: http://www.frontiersin.org/journal/10.3389/fchem. 2014.00069/abstract

\section{REFERENCES}

Adamis, A. P., Altaweel, M., Bressler, N. M., Cunningham, E. T., Davis, M. D., Goldbaum, M., et al. (2006). Changes in retinal neovascularization after pegaptanib (Macugen) therapy in diabetic individuals. Ophthalmology 113, 23-28. doi: 10.1016/j.ophtha.2005.10.012

Allen, T. M. (2002). Ligand-targeted therapeutics in anticancer therapy. Nat. Rev. Cancer 2, 750-763. doi: 10.1038/nrc903

Ando, M., Yonemori, K., Katsumata, N., Shimizu, C., Hirata, T., Yamamoto, H., et al. (2012). Phase I and pharmacokinetic study of nab-paclitaxel, nanoparticle albumin-bound paclitaxel, administered weekly to Japanese patients with solid tumors and metastatic breast cancer. Cancer Chemother. Pharmacol. 69, 457-465. doi: 10.1007/s00280-011-1726-5

Arruebo, M., Fernández-Pacheco, R., Ibarra, M. R., and Santamaría, J. (2007). Magnetic nanoparticles for drug delivery. Nano Today 2, 22-32. doi: 10.1016/S1748-0132(07)70084-1

Arruebo, M., Valladares, M., and Gonzalez-Fernandez, A. (2009). Antibodyconjugated nanoparticles for biomedical applications. J. Nanomat. 2009:439389. doi: $10.1155 / 2009 / 439389$

Arvizo, R., Bhattacharya, R., and Mukherjee, P. (2010). Gold nanoparticles: opportunities and challenges in nanomedicine. Expert Opin. Drug Deliv. 7, 753-763. doi: 10.1517/17425241003777010

Balogh, L., Nigavekar, S. S., Nair, B. M., Lesniak, W., Zhang, C., Sung, L. Y., et al. (2007). Significant effect of size on the in vivo biodistribution of gold composite nanodevices in mouse tumor models. Nanomed. Nanotechnol. Biol. Med. 3, 281-296. doi: 10.1016/j.nano.2007.09.001

Banerjee, R., Katsenovich, Y., Lagos, L., Mclintosh, M., Zhang, X., and Li, C. Z. (2010). Nanomedicine: magnetic nanoparticles and their biomedical applications. Curr. Med. Chem. 17, 3120-3141. doi: 10.2174/092986710791959765

Banerjee, S. R., Foss, C. A., Castanares, M., Mease, R. C., Byun, Y., Fox, J. J., et al. (2008). Synthesis and evaluation of technetium-99m-and rhenium-labeled inhibitors of the prostate-specific membrane antigen (PSMA). J. Med. Chem. 51, 4504-4517. doi: 10.1021/jm800111u

Barenholz, Y. (2012). Doxil(R)-the first FDA-approved nano-drug: lessons learned. J. Control. Release 160, 117-134. doi: 10.1016/j.jconrel.2012.03.020
Bedikian, A. Y., Silverman, J. A., Papadopoulos, N. E., Kim, K. B., Hagey, A. E., Vardeleon, A., et al. (2011). Pharmacokinetics and safety of marqibo (vincristine sulfate liposomes injection) in cancer patients with impaired liver function. J. Clin. Pharmacol. 51, 1205-1212. doi: 10.1177/0091270010381499

Bellott, R., Auvrignon, A., Leblanc, T., Perel, Y., Gandemer, V., Bertrand, Y., et al. (2001). Pharmacokinetics of liposomal daunorubicin [DaunoXome] during a phase I-II study in children with relapsed acute lymphoblastic leukaemia. Cancer Chemother. Pharmacol. 47, 15-21. doi: 10.1007/s002800000206

Benezra, M., Penate-Medina, O., Zanzonico, P. B., Schaer, D., Ow, H., Burns, A., et al. (2011). Multimodal silica nanoparticles are effective cancer-targeted probes in a model of human melanoma. J. Clin. Invest. 121, 2768-2780. doi: $10.1172 / \mathrm{JCI} 45600$

Blanco, E., Bey, E. A., Khemtong, C., Yang, S. G., Setti-Guthi, J., Chen, H. B., et al. (2010). Beta-lapachone micellar nanotherapeutics for non-small cell lung cancer therapy. Cancer Res. 70, 3896-3904. doi: 10.1158/0008-5472.CAN-09-3995

Boisselier, E., and Astruc, D. (2009). Gold nanoparticles in nanomedicine: preparations, imaging, diagnostics, therapies and toxicity. Chem. Soc. Rev. 38, 1759-1782. doi: 10.1039/b806051g

Bradley, A. M., Devine, M., and Deremer, D. (2013). Brentuximab vedotin: an antiCD30 antibody-drug conjugate. Am. J. Health Syst. Pharm. 70, 589-597. doi: 10.2146/ajhp110608

Bunka, D. H. J., and Stockley, P. G. (2006). Aptamers come of age-at last. Nat. Rev. Microbiol. 4, 588-596. doi: 10.1038/nrmicro1458

Burns, A., Ow, H., and Wiesner, U. (2006). Fluorescent core-shell silica nanoparticles: towards "Lab on a Particle" architectures for nanobiotechnology. Chem. Soc. Rev. 35, 1028-1042. doi: 10.1039/b600562b

Chames, P., Van Regenmortel, M., Weiss, E., and Baty, D. (2009). Therapeutic antibodies: successes, limitations and hopes for the future. Br. J. Pharmacol. 157, 220-233. doi: 10.1111/j.1476-5381.2009.00190.x

Chanda, N., Kattumuri, V., Shukla, R., Zambre, A., Katti, K., Upendran, A., et al. (2010). Bombesin functionalized gold nanoparticles show in vitro and in vivo cancer receptor specificity. Proc. Natl. Acad. Sci. U.S.A. 107, 8760-8765. doi: 10.1073/pnas.1002143107

Chattopadhyay, N., Fonge, H., Cai, Z., Scollard, D., Lechtman, E., Done, S. J., et al. (2012). Role of antibody-mediated tumor targeting and route of administration in nanoparticle tumor accumulation in vivo. Mol. Pharm. 9, 2168-2179. doi: $10.1021 / \mathrm{mp} 300016 \mathrm{p}$

Chen, F., Hong, H., Zhang, Y., Valdovinos, H. F., Shi, S. X., Kwon, G. S., et al. (2013). In vivo tumor targeting and image-guided drug delivery with antibody-conjugated, radio labeled mesoporous silica nanoparticles. ACS Nano 7, 9027-9039. doi: 10.1021/nn403617j

Chen, L. C., Wu, Y. H., Liu, I. H., Ho, C. L., Lee, W. C., Chang, C. H., et al. (2012a). Pharmacokinetics, dosimetry and comparative efficacy of Re-188-liposome and 5-FU in a CT26-luc lung-metastatic mice model. Nucl. Med. Biol. 39, 35-43. doi: 10.1016/j.nucmedbio.2011.06.010

Chen, M., Fang, X. L., Tang, S. H., and Zheng, N. F. (2012b). Polypyrrole nanoparticles for high-performance in vivo near-infrared photothermal cancer therapy. Chem. Commun. 48, 8934-8936. doi: 10.1039/c2cc34463g

Cheng, K., Kothapalli, S. R., Liu, H. G., Koh, A. L., Jokerst, J. V., Jiang, H., et al. (2014). Construction and validation of nano gold tripods for molecular imaging of living subjects. J. Am. Chem. Soc. 136, 3560-3571. doi: 10.1021/ja41 2001e

Cho, K., Wang, X., Nie, S., Chen, Z. G., and Shin, D. M. (2008). Therapeutic nanoparticles for drug delivery in cancer. Clin. Cancer Res. 14, 1310-1316. doi: 10.1158/1078-0432.CCR-07-1441

Choi, C. H. J., Alabi, C. A., Webster, P., and Davis, M. E. (2010). Mechanism of active targeting in solid tumors with transferrin-containing gold nanoparticles. Proc. Natl. Acad. Sci. U.S.A. 107, 1235-1240. doi: 10.1073/pnas.09141 40107

Coimbra, M., Rijcken, C. J. F., Stigter, M., Hennink, W. E., Storm, G. and Schiffelers, R. M. (2012). Antitumor efficacy of dexamethasone-loaded core-crosslinked polymeric micelles. J. Control. Release 163, 361-367. doi: 10.1016/j.jconrel.2012.09.014

Cornelissen, B., Able, S., Kersemans, V., Waghorn, P. A., Myhra, S., Jurkshat, K., et al. (2013). Nanographene oxide-based radioimmunoconstructs for in vivo targeting and SPECT imaging of HER2-positive tumors. Biomaterials 34, 1146-1154. doi: 10.1016/j.biomaterials.2012.10.054

Daniels, T. R., Bernabeu, E., Rodriguez, J. A., Patel, S., Kozman, M., Chiappetta, D. A., et al. (2012). The transferrin receptor and the targeted delivery of 
therapeutic agents against cancer. Biochim. Biophys. Acta 1820, 291-317. doi: 10.1016/j.bbagen.2011.07.016

Davis, M. E., Chen, Z., and Shin, D. M. (2008). Nanoparticle therapeutics: an emerging treatment modality for cancer. Nat. Rev. Drug Discov. 7, 771-782. doi: $10.1038 / \mathrm{nrd} 2614$

Dawidczyk, C. M., Kim, C., Park, J. H., Russell, L. M., Lee, K. H., Pomper, M. G., et al. (2014). State-of-the-art in design rules for drug delivery platforms: lessons learned from FDA-approved nanomedicines. J. Control. Release 187, 133-144. doi: 10.1016/j.jconrel.2014.05.036

Dechantsreiter, M. A., Planker, E., Matha, B., Lohof, E., Holzemann, G., Jonczyk, A., et al. (1999). N-methylated cyclic RGD peptides as highly active and selective alpha(v)beta(3) integrin antagonists. J. Med. Chem. 42, 3033-3040. doi: $10.1021 / \mathrm{jm} 970832 \mathrm{~g}$

Dill, K., Lin, M., Poteras, C., Fraser, C., Hafeman, D. G., Owicki, J. C., et al. (1994). Antibody-antigen binding constants determined in solution-phase with the threshold membrane-capture system - binding constants for antifluorescein, anti-saxitoxin, and anti-ricin antibodies. Anal. Biochem. 217, 128-138. doi: 10.1006/abio.1994.1093

Di Pasqua, A. J., Miller, M. L., Lu, X. L., Peng, L., and Jay, M. (2012). Tumor accumulation of neutron-activatable holmium-containing mesoporous silica nanoparticles in an orthotopic non-small cell lung cancer mouse model. Inorganica Chim. Acta 393, 334-336. doi: 10.1016/j.ica.2012.06.016

Duncan, R. (2006). Polymer conjugates as anticancer nanomedicines. Nat. Rev. Cancer 6, 688-701. doi: 10.1038/nrc1958

Erttmann, R., Erb, N., Steinhoff, A., and Landbeck, G. (1988). Pharmacokinetics of doxorubicin in man: dose and schedule dependence. J. Cancer Res. Clin. Oncol. 114, 509-513. doi: 10.1007/BF00391502

Fang, J., Nakamura, H., and Maeda, H. (2011). The EPR effect: unique features of tumor blood vessels for drug delivery, factors involved, and limitations and augmentation of the effect. Adv. Drug Deliv. Rev. 63, 136-151. doi: 10.1016/j.addr.2010.04.009

Fonge, H., Huang, H., Scollard, D., Reilly, R. M., and Allen, C. (2012). Influence of formulation variables on the biodistribution of multifunctional block copolymer micelles. J. Control. Release 157, 366-374. doi: 10.1016/j.jconrel.2011.09.088

Frese, K. K., and Tuveson, D. A. (2007). Maximizing mouse cancer models. Nat. Rev. Cancer 7, 645-658. doi: 10.1038/nrc2192

Fuchs, S., and Coester, C. (2010). Protein-based nanoparticles as a drug delivery system: chances, risks, perspectives. J. Drug Deliv. Sci. Technol. 20, 331-342.

Furger, K. A., Allan, A. L., Wilson, S. M., Hota, C., Vantyghem, S. A., Postenka, C. O., et al. (2003). Beta(3) integrin expression increases breast carcinoma cell responsiveness to the malignancy-enhancing effects of osteopontin. Mol. Cancer Res. 1, 810-819.

Gabizon, A., Catane, R., Uziely, B., Kaufman, B., Safra, T., Cohen, R., et al. (1994). Prolonged circulation time and enhanced accumulation in malignant exudates of doxorubicin encapsulated in polyethylene-glycol coated liposomes. Cancer Res. 54, 987-992.

Gabizon, A., Shmeeda, H., and Barenholz, Y. (2003). Pharmacokinetics of pegylated liposomal Doxorubicin: review of animal and human studies. Clin. Pharmacokinet. 42, 419-436. doi: 10.2165/00003088-200342050-00002

Gao, J. H., Chen, K., Xie, R. G., Xie, J., Yan, Y. J., Cheng, Z., et al. (2010). In vivo tumor-targeted fluorescence imaging using near-infrared non-cadmium quantum dots. Bioconjug. Chem. 21, 604-609. doi: 10.1021/bc900323v

Gao, X. H., Cui, Y. Y., Levenson, R. M., Chung, L. W. K., and Nie, S. M. (2004). In vivo cancer targeting and imaging with semiconductor quantum dots. Nat. Biotechnol. 22, 969-976. doi: 10.1038/nbt994

Gill, P. S., Wernz, J., Scadden, D. T., Cohen, P., Mukwaya, G. M., Von Roenn, J. H., et al. (1996). Randomized phase III trial of liposomal daunorubicin versus doxorubicin, bleomycin, and vincristine in AIDS-related Kaposi's sarcoma. J. Clin. Oncol. 14, 2353-2364.

Giri, S., Trewyn, B. G., and Lin, V. S. Y. (2007). Mesoporous silica nanomaterialbased biotechnological and biomedical delivery systems. Nanomedicine 2, 99-111. doi: 10.2217/17435889.2.1.99

Giri, S., Trewyn, B. G., Stellmaker, M. P., and Lin, V. S. (2005). Stimuli-responsive controlled-release delivery system based on mesoporous silica nanorods capped with magnetic nanoparticles. Angew. Chem. Int. Ed. Engl. 44, 5038-5044. doi: 10.1002/anie. 200501819

Girish, S., Gupta, M., Wang, B., Lu, D., Krop, I. E., Vogel, C. L., et al. (2012). Clinical pharmacology of trastuzumab emtansine (T-DM1): an antibody-drug conjugate in development for the treatment of HER2-positive cancer. Cancer Chemother. Pharmacol. 69, 1229-1240. doi: 10.1007/s00280-011-1817-3

Greco, F., and Vicent, M. J. (2009). Combination therapy: opportunities and challenges for polymer-drug conjugates as anticancer nanomedicines. Adv. Drug Deliv. Rev. 61, 1203-1213. doi: 10.1016/j.addr.2009.05.006

Hainfeld, J. F., Slatkin, D. N., Focella, T. M., and Smilowitz, H. M. (2006). Gold nanoparticles: a new X-ray contrast agent. Br. J. Radiol. 79, 248-253. doi: 10.1259/bjr/13169882

Hamilton, A., Biganzoli, L., Coleman, R., Mauriac, L., Hennebert, P., Awada, A., et al. (2002). EORTC 10968: a phase I clinical and pharmacokinetic study of polyethylene glycol liposomal doxorubicin (Caelyx, Doxil) at a 6-week interval in patients with metastatic breast cancer. European organization for research and treatment of cancer. Ann. Oncol. 13, 910-918. doi: 10.1093/annonc/mdf157

Hanahan, D., and Weinberg, R. A. (2011). Hallmarks of cancer: the next generation. Cell 144, 646-674. doi: 10.1016/j.cell.2011.02.013

Harrington, K. J., Rowlinson-Busza, G., Syrigos, K. N., Abra, R. M., Uster, P. S., Peters, A. M., et al. (2000). Influence of tumour size on uptake of In-111-DTPAlabelled pegylated liposomes in a human tumour xenograft model. Br. J. Cancer 83, 684-688. doi: 10.1054/bjoc.2000.1320

Hartmann, L. C., Keeney, G. L., Lingle, W. L., Christianson, T. J. H., Varghese, B., Hillman, D., et al. (2007). Folate receptor overexpression is associated with poor outcome in breast cancer. Int. J. Cancer 121, 938-942. doi: 10.1002/ijc.22811

Haubner, R., Gratias, R., Diefenbach, B., Goodman, S. L., Jonczyk, A., and Kessler, H. (1996). Structural and functional aspects of RGD-containing cyclic pentapeptides as highly potent and selective integrin alpha(v)beta(3) antagonists. J. Am. Chem. Soc. 118, 7461-7472. doi: 10.1021/ja9603721

Haun, J. B., Yoon, T. J., Lee, H., and Weissleder, R. (2010). Magnetic nanoparticle biosensors. Wiley Interdiscip. Rev. Nanome. Nanobiotechnol. 2, 291-304. doi: 10.1002/wnan.84

Helbok, A., Rangger, C., Von Guggenberg, E., Saba-Lepek, M., Radolf, T., Thurner, G., et al. (2012). Targeting properties of peptide-modified radiolabeled liposomal nanoparticles. Nanomedicine 8, 112-118. doi: 10.1016/j.nano.2011.04.012

Hilgenbrink, A. R., and Low, P. S. (2005). Folate receptor-mediated drug targeting: from therapeutics to diagnostics. J. Pharm. Sci. 94, 2135-2146. doi: 10.1002/jps.20457

Hoang, B., Lee, H., Reilly, R. M., and Allen, C. (2009). Noninvasive monitoring of the fate of in-111-labeled block copolymer micelles by high resolution and high sensitivity MicroSPECT/CT imaging. Mol. Pharm. 6, 581-592. doi: $10.1021 / \mathrm{mp} 8002418$

Holliger, P., and Hudson, P. J. (2005). Engineered antibody fragments and the rise of single domains. Nat. Biotechnol. 23, 1126-1136. doi: 10.1038/nbt1142

Hong, H., Yang, K., Zhang, Y., Engle, J. W., Feng, L., Yang, Y., et al. (2012). In vivo targeting and imaging of tumor vasculature with radiolabeled, antibodyconjugated nanographene. ACS Nano 6, 2361-2370. doi: 10.1021/nn204625e

Hong, R. L., and Tseng, Y. L. (2001). Phase I and pharmacokinetic study of a stable, polyethylene-glycolated liposomal doxorubicin in patients with solid tumors: the relation between pharmacokinetic property and toxicity. Cancer 91, 1826-1833. doi: 10.1002/1097-0142(20010501)91:9<1826::AIDCNCR1203>3.0.CO;2-J

Horcajada, P., Gref, R., Baati, T., Allan, P. K., Maurin, G., Couvreur, P., et al. (2012). Metal-organic frameworks in biomedicine. Chem. Rev. 112, 1232-1268. doi $10.1021 / \mathrm{cr} 200256 \mathrm{v}$

Hosotani, R., Kawaguchi, M., Masui, T., Koshiba, T., Ida, J., Fujimoto, K., et al. (2002). Expression of integrin alphaVbeta3 in pancreatic carcinoma: relation to MMP-2 activation and lymph node metastasis. Pancreas 25, e30-e35. doi: 10.1097/00006676-200208000-00021

Hsu, C. W., Chang, Y. J., Chang, C. H., Chen, L. C., Lan, K. L., Ting, G., et al. (2012). Comparative therapeutic efficacy of rhenium-188 radiolabeled-liposome and 5fluorouracil in LS-174T human colon carcinoma solid tumor xenografts. Cancer Biother. Radiopharm. 27, 481-489. doi: 10.1089/cbr.2011.1158

$\mathrm{Hu}, \mathrm{M}$., and Zhang, K. (2013). The application of aptamers in cancer research: an up-to-date review. Future Oncol. 9, 369-376. doi: 10.2217/fon.12.201

Hu, Z., Luo, F., Pan, Y., Hou, C., Ren, L., Chen, J., et al. (2008). Arg-Gly-Asp (RGD) peptide conjugated poly(lactic acid)-poly(ethylene oxide) micelle for targeted drug delivery. J. Biomed. Mater. Res. A 85, 797-807. doi: 10.1002/jbm.a.31615

Huang, F. Y. J., Lee, T. W., Kao, C. H. K., Chang, C. H., Zhang, X. N., Lee, W. Y., et al. (2011). Imaging, autoradiography, and biodistribution of Re188-labeled PEGylated nanoliposome in orthotopic glioma bearing rat model. Cancer Biother. Radiopharm. 26, 717-725. doi: 10.1089/cbr.2011.1052 
Hubert, A., Lyass, O., Pode, D., and Gabizon, A. (2000). Doxil (Caelyx): an exploratory study with pharmacokinetics in patients with hormone-refractory prostate cancer. Anticancer Drugs 11, 123-127. doi: 10.1097/00001813200002000-00009

Huynh, N. T., Roger, E., Lautram, N., Benoit, J. P., and Passirani, C. (2010). The rise and rise of stealth nanocarriers for cancer therapy: passive versus active targeting. Nanomedicine (Lond). 5, 1415-1433. doi: 10.2217/nnm.10.113

Hynes, R. O. (2002). Integrins: bidirectional, allosteric signaling machines. Cell 110, 673-687. doi: 10.1016/S0092-8674(02)00971-6

Immordino, M. L., Dosio, F., and Cattel, L. (2006). Stealth liposomes: review of the basic science, rationale, and clinical applications, existing and potential. Int. J. Nanomedicine 1, 297-315.

Iyer, A. K., Su, Y., Feng, J., Lan, X., Zhu, X., Liu, Y., et al. (2011). The effect of internalizing human single chain antibody fragment on liposome targeting to epithelioid and sarcomatoid mesothelioma. Biomaterials 32, 2605-2613. doi: 10.1016/j.biomaterials.2010.11.073

Jacquet, J. M., Bressolle, F., Galtier, M., Bourrier, M., Donadio, D., Jourdan, J., et al. (1990). Doxorubicin and doxorubicinol: intra- and inter-individual variations of pharmacokinetic parameters. Cancer Chemother. Pharmacol. 27, 219-225. doi: $10.1007 / \mathrm{BF} 00685716$

Jain, K. K. (2012). Advances in use of functionalized carbon nanotubes for drug design and discovery. Expert Opin. Drug Discov. 7, 1029-1037. doi: $10.1517 / 17460441.2012 .722078$

Jain, R. K. (2005). Normalization of tumor vasculature: an emerging concept in antiangiogenic therapy. Science 307, 58-62. doi: 10.1126/science.1104819

Jain, R. K., and Stylianopoulos, T. (2010). Delivering nanomedicine to solid tumors. Nat. Rev. Clin. Oncol. 7, 653-664. doi: 10.1038/nrclinonc.2010.139

Jones, C. H., Chen, C. K., Ravikrishnan, A., Rane, S., and Pfeifer, B. A. (2013) Overcoming nonviral gene delivery barriers: perspective and future. Mol. Pharm. 10, 4082-4098. doi: 10.1021/mp400467x

Kamen, B. A., and Smith, A. K. (2004). A review of folate receptor alpha cycling and 5-methyltetrahydrofolate accumulation with an emphasis on cell models in vitro. Adv. Drug Deliv. Rev. 56, 1085-1097. doi: 10.1016/j.addr.2004. 01.002

Kawano, K., Watanabe, M., Yamamoto, T., Yokoyama, M., Opanasopit, P., Okano, T., et al. (2006). Enhanced antitumor effect of camptothecin loaded in long-circulating polymeric micelles. J. Control. Release 112, 329-332. doi: 10.1016/j.jconrel.2006.03.012

Keefe, A. D., Pai, S., and Ellington, A. (2010). Aptamers as therapeutics. Nat. Rev. Drug Discov. 9, 537-550. doi: 10.1038/nrd3141

Kheirolomoom, A., Mahakian, L. M., Lai, C. Y., Lindfors, H. A., Seo, J. W., Paoli, E. E., et al. (2010). Copper-doxorubicin as a nanoparticle cargo retains efficacy with minimal toxicity. Mol. Pharm. 7, 1948-1958. doi: 10.1021/ mp100245u

Khemtong, C., Kessinger, C. W., Ren, J., Bey, E. A., Yang, S. G., Guthi, J. S., et al. (2009). In vivo off-resonance saturation magnetic resonance imaging of alphavbeta3-targeted superparamagnetic nanoparticles. Cancer Res. 69, 1651-1658. doi: 10.1158/0008-5472.CAN-08-3231

Kim, S. H., Jeong, J. H., Lee, S. H., Kim, S. W., and Park, T. G. (2008). Local and systemic delivery of VEGF siRNA using polyelectrolyte complex micelles for effective treatment of cancer. J. Control. Release 129, 107-116. doi: 10.1016/j.jconrel.2008.03.008

Knop, K., Hoogenboom, R., Fischer, D., and Schubert, U. S. (2010). Poly(ethylene glycol) in drug delivery: pros and cons as well as potential alternatives. Angew. Chem. Int. Ed. Engl. 49, 6288-6308. doi: 10.1002/anie.200902672

Kresse, M., Wagner, S., Pfefferer, D., Lawaczeck, R., Elste, V., and Semmler, W. (1998). Targeting of ultrasmall superparamagnetic iron oxide (USPIO) particles to tumor cells in vivo by using transferrin receptor pathways. Magn. Reson. Med. 40, 236-242. doi: 10.1002/mrm.1910400209

Krogh-Madsen, M., Bender, B., Jensen, M. K., Nielsen, O. J., Friberg, L. E., and Honore, P. H. (2012). Population pharmacokinetics of cytarabine, etoposide, and daunorubicin in the treatment for acute myeloid leukemia. Cancer Chemother. Pharmacol. 69, 1155-1163. doi: 10.1007/s00280-011-1800-Z

Kumar, M., Yigit, M., Dai, G. P., Moore, A., and Medarova, Z. (2010). Image-guided breast tumor therapy using a small interfering RNA nanodrug. Cancer Res. 70, 7553-7561. doi: 10.1158/0008-5472.CAN-10-2070

Kunjachan, S., Pola, R., Gremse, F., Theek, B., Ehling, J., Moeckel, D., et al. (2014). Passive versus active tumor targeting using RGD- and NGR-modified polymeric nanomedicines. Nano Lett. 14, 972-981. doi: 10.1021/nl404391r
Lasic, D. D., Frederik, P. M., Stuart, M. C., Barenholz, Y., and McIntosh, T. J. (1992). Gelation of liposome interior. A novel method for drug encapsulation. FEBS Lett. 312, 255-258. doi: 10.1016/0014-5793(92)80947-F

Le Garrec, D., Taillefer, J., Van Lier, J. E., Lenaerts, V., and Leroux, J. C. (2002). Optimizing pH-responsive polymeric micelles for drug delivery in a cancer photodynamic therapy model. J. Drug Target. 10, 429-437. doi: $10.1080 / 1061186021000001887$

Libutti, S. K., Paciotti, G. F., Byrnes, A. A., Alexander, H. R., Gannon, W. E., Walker, M., et al. (2010). Phase I and Pharmacokinetic Studies of CYT-6091, a Novel PEGylated Colloidal Gold-rhTNF Nanomedicine. Clin. Cancer Res.16, 6139-6149. doi: 10.1158/1078-0432.CCR-10-0978

Liechty, W. B., and Peppas, N. A. (2012). Expert opinion: responsive polymer nanoparticles in cancer therapy. Eur. J. Pharm. Biopharm. 80, 241-246. doi: 10.1016/j.ejpb.2011.08.004

Liu, X. W., Tao, H. Q., Yang, K., Zhang, S. A., Lee, S. T., and Liu, Z. A. (2011). Optimization of surface chemistry on single-walled carbon nanotubes for in vivo photothermal ablation of tumors. Biomaterials 32, 144-151. doi: 10.1016/j.biomaterials.2010.08.096

Lorusso, P. M., Weiss, D., Guardino, E., Girish, S., and Sliwkowski, M. X. (2011). Trastuzumab emtansine: a unique antibody-drug conjugate in development for human epidermal growth factor receptor 2-positive cancer. Clin. Cancer Res. 17, 6437-6447. doi: 10.1158/1078-0432.CCR-11-0762

Lowis, S., Lewis, I., Elsworth, A., Weston, C., Doz, F., Vassal, G., et al. (2006). A phase I study of intravenous liposomal daunorubicin (DaunoXome) in paediatric patients with relapsed or resistant solid tumours. Br. J. Cancer 95, 571-580. doi: 10.1038/sj.bjc.6603288

Lu, D., Burris, H. A., Wang, B., Dees, E. C., Cortes, J., Joshi, A., et al. (2012). Drug interaction potential of trastuzumab emtansine (T-DM1) combined with pertuzumab in patients with HER2-positive metastatic breast cancer. Curr. Drug Metab. 13, 911-922. doi: 10.2174/138920012802138688

Lu, W., Xiong, C., Zhang, G., Huang, Q., Zhang, R., Zhang, J. Z., et al. (2009). Targeted photothermal ablation of murine melanomas with melanocytestimulating hormone analog-conjugated hollow gold nanospheres. Clin. Cancer Res. 15, 876-886. doi: 10.1158/1078-0432.CCR-08-1480

Lu, W., Zhang, G., Zhang, R., Flores, L. G., Huang, Q., Gelovani, J. G., et al. (2010). Tumor site-specific silencing of NF-kappaB p65 by targeted hollow gold nanosphere-mediated photothermal transfection. Cancer Res. 70, 3177-3188. doi: 10.1158/0008-5472.CAN-09-3379

Lupold, S. E., Hicke, B. J., Lin, Y., and Coffey, D. S. (2002). Identification and characterization of nuclease-stabilized RNA molecules that bind human prostate cancer cells via the prostate-specific membrane antigen. Cancer Res 62, 4029-4033. doi: 10.1158/0008-5472.Can-12-2152

Lyass, O., Uziely, B., Ben-Yosef, R., Tzemach, D., Heshing, N. I., Lotem, M., et al. (2000). Correlation of toxicity with pharmacokinetics of pegylated liposomal doxorubicin (Doxil) in metastatic breast carcinoma. Cancer 89, 1037-1047. doi: 10.1002/1097-0142(20000901)89:5<1037::AID-CNCR13>3.0.CO;2-Z

Mahakian, L. M., Farwell, D. G., Zhang, H., Seo, J. W., Poirier, B., Tinling, S. P., et al. (2014). Comparison of PET Imaging with Cu-64-Liposomes and F-18-FDG in the 7,12-Dimethylbenz[a] anthracene (DMBA)-induced hamster buccal pouch model of oral dysplasia and squamous cell carcinoma. Mol. Imaging Biol. 16, 284-292. doi: 10.1007/s11307-013-0676-1

Medintz, I. L., Uyeda, H. T., Goldman, E. R., and Mattoussi, H. (2005). Quantum dot bioconjugates for imaging, labelling and sensing. Nat. Mater. 4, 435-446. doi: 10.1038/nmat1390

Melancon, M. P., Lu, W., Yang, Z., Zhang, R., Cheng, Z., Elliot, A. M., et al. (2008). In vitro and in vivo targeting of hollow gold nanoshells directed at epidermal growth factor receptor for photothermal ablation therapy. Mol. Cancer Ther. 7, 1730-1739. doi: 10.1158/1535-7163.MCT-08-0016

Michalet, X., Pinaud, F. F., Bentolila, L. A., Tsay, J. M., Doose, S., Li, J. J., et al. (2005). Quantum dots for live cells, in vivo imaging, and diagnostics. Science 307, 538-544. doi: 10.1126/science.1104274

Miele, E., Spinelli, G. P., Miele, E., Tomao, F., and Tomao, S. (2009). Albuminbound formulation of paclitaxel (Abraxane ABI-007) in the treatment of breast cancer. Int. J. Nanomedicine 4, 99-105.

Miller, T., Breyer, S., Van Colen, G., Mier, W., Haberkorn, U., Geissler, S., et al. (2013). Premature drug release of polymeric micelles and its effects on tumor targeting. Int. J. Pharm. 445, 117-124. doi: 10.1016/j.ijpharm.2013.01.059

Mintzer, M. A., and Simanek, E. E. (2009). Nonviral vectors for gene delivery. Chem. Rev. 109, 259-302. doi: 10.1021/cr800409e 
Morales-Avila, E., Ferro-Flores, G., Ocampo-Garcia, B. E., De Leon-Rodriguez, L. M., Santos-Cuevas, C. L., Garcia-Becerra, R., et al. (2011). Multimeric system of $99 \mathrm{mTc}$-labeled gold nanoparticles conjugated to $\mathrm{c}[\mathrm{RGDfK}(\mathrm{C})]$ for molecular imaging of tumor alpha(v)beta(3) expression. Bioconjug. Chem. 22, 913-922. doi: $10.1021 / \mathrm{bc} 100551 \mathrm{~s}$

Mullard, A. (2013). Maturing antibody-drug conjugate pipeline hits 30. Nat. Rev. Drug Discov. 12, 329-332. doi: 10.1038/nrd4009

Muller, C., and Schibli, R. (2013). Prospects in folate receptor-targeted radionuclide therapy. Front. Oncol. 3:249. doi: 10.3389/fonc.2013.00249

Natarajan, A., Gruettner, C., Ivkov, R., Denardo, G. L., Mirick, G., Yuan, A., et al. (2008). NanoFerrite particle based radioimmunonanoparticles: binding affinity and in vivo pharmacokinetics. Bioconjug. Chem. 19, 1211-1218. doi: $10.1021 / \mathrm{bc} 800015 \mathrm{n}$

Naumann, R. W., Coleman, R. L., Burger, R. A., Sausville, E. A., Kutarska, E., Ghamande, S. A., et al. (2013). PRECEDENT: a randomized phase ii trial comparing vintafolide (EC145) and Pegylated Liposomal Doxorubicin (PLD) in combination versus PLD alone in patients with platinum-resistant ovarian cancer. J. Clin. Oncol. 31, 4400-4406. doi: 10.1200/JCO.2013.49.7685

Nicolas, J., Mura, S., Brambilla, D., Mackiewicz, N., and Couvreur, P. (2013). Design, functionalization strategies and biomedical applications of targeted biodegradable/biocompatible polymer-based nanocarriers for drug delivery. Chem. Soc. Rev. 42, 1147-1235. doi: 10.1039/c2cs35265f

Niemeyer, C. M. (2001). Nanoparticles, proteins, and nucleic acids: biotechnology meets materials science. Angew. Chem. Int. Ed. Engl. 40, 4128-4158. doi: 10.1002/1521-3773(20011119)40:22<4128::AID-ANIE4128>3.0.CO;2-S

Novio, F., Simmchen, J., Vazquez-Mera, N., Amorin-Ferre, L., and Ruiz-Molina, D. (2013). Coordination polymer nanoparticles in medicine. Coord. Chem. Rev. 257, 2839-2847. doi: 10.1016/j.ccr.2013.04.022

Ohguchi, Y., Kawano, K., Hattori, Y., and Maitani, Y. (2008). Selective delivery of folate-PEG-linked, nanoemulsion-loaded aclacinomycin A to KB nasopharyngeal cells and xenograft: effect of chain length and amount of folate-PEG linker. J. Drug Target. 16, 660-667. doi: 10.1080/10611860802201464

Ohno, K., Mori, C., Akashi, T., Yoshida, S., Tago, Y., Tsujii, Y., et al. (2013). Fabrication of contrast agents for magnetic resonance imaging from polymerbrush-afforded iron oxide magnetic nanoparticles prepared by surfaceinitiated living radical polymerization. Biomacromolecules 14, 3453-3462. doi: 10.1021/bm400770n

Oyewumi, M. O., Yokel, R. A., Jay, M., Coakley, T., and Mumper, R. J. (2004). Comparison of cell uptake, biodistribution and tumor retention of folate-coated and PEG-coated gadolinium nanoparticles in tumor-bearing mice. J. Control. Release 95, 613-626. doi: 10.1016/j.jconrel.2004.01.002

Pack, D. W., Hoffman, A. S., Pun, S., and Stayton, P. S. (2005). Design and development of polymers for gene delivery. Nat. Rev. Drug Discov. 4, 581-593. doi: $10.1038 /$ nrd 1775

Paraskar, A., Soni, S., Roy, B., Papa, A. L., and Sengupta, S. (2012). Rationally designed oxaliplatin-nanoparticle for enhanced antitumor efficacy. Nanotechnology 23:075103. doi: 10.1088/0957-4484/23/7/075103

Park, J., Dvoracek, C., Lee, K. H., Galloway, J. F., Bhang, H. E. C., Pomper, M. G., et al. (2011). CuInSe/ZnS Core/Shell NIR quantum dots for biomedical imaging. Small 7, 3148-3152. doi: 10.1002/smll.201101558

Parker, N., Turk, M. J., Westrick, E., Lewis, J. D., Low, P. S., and Leamon, C. P. (2005). Folate receptor expression in carcinomas and normal tissues determined by a quantitative radioligand binding assay. Anal. Biochem. 338, 284-293. doi: 10.1016/j.ab.2004.12.026

Penate Medina, O., Haikola, M., Tahtinen, M., Simpura, I., Kaukinen, S., Valtanen, H., et al. (2011). Liposomal tumor targeting in drug delivery utilizing MMP-2- and MMP-9-binding ligands. J. Drug Deliv. 2011, 160515. doi: $10.1155 / 2011 / 160515$

Petersen, A. L., Binderup, T., Jolck, R. I., Rasmussen, P., Henriksen, J. R., Pfeifer, A. K., et al. (2012). Positron emission tomography evaluation of somatostatin receptor targeted 64Cu-TATE-liposomes in a human neuroendocrine carcinoma mouse model. J. Control. Release 160, 254-263. doi: 10.1016/j.jconrel.2011.12.038

Petryayeva, E., Algar, W. R., and Medintz, I. L. (2013). Quantum dots in bioanalysis: a review of applications across various platforms for fluorescence spectroscopy and imaging. Appl. Spectrosc. 67, 215-252. doi: 10.1366/12-06948

Piscitelli, S. C., Rodvold, K. A., Rushing, D. A., and Tewksbury, D. A. (1993). Pharmacokinetics and pharmacodynamics of doxorubicin in patients with small cell lung cancer. Clin. Pharmacol. Ther. 53, 555-561. doi: 10.1038/clpt.1993.69
Poon, Z., Lee, J. A., Huang, S., Prevost, R. J., and Hammond, P. T. (2011). Highly stable, ligand-clustered "patchy" micelle nanocarriers for systemic tumor targeting. Nanomedicine 7, 201-209. doi: 10.1016/j.nano.2010.07.008

Prato, M., Kostarelos, K., and Bianco, A. (2008). Functionalized carbon nanotubes in drug design and discovery. Acc. Chem. Res. 41, 60-68. doi: 10.1021/ar700089b

Puvanakrishnan, P., Park, J., Chatterjee, D., Krishnan, S., and Tunnell, J. W. (2012). In vivo tumor targeting of gold nanoparticles: effect of particle type and dosing strategy. Int. J. Nanomedicine 7, 1251-1258. doi: 10.2147/IJN.S29147

Reddy, L. H., Sharma, R. K., and Murthy, R. R. (2006). Enhanced delivery of etoposide to Dalton's lymphoma in mice through polysorbate 20 micelles. Acta Pharm. 56, 143-155.

Rijcken, C. J., Snel, C. J., Schiffelers, R. M., Van Nostrum, C. F., and Hennink, W. E. (2007). Hydrolysable core-crosslinked thermosensitive polymeric micelles: synthesis, characterisation and in vivo studies. Biomaterials 28, 5581-5593. doi: 10.1016/j.biomaterials.2007.08.047

Robinson, J. T., Hong, G. S., Liang, Y. Y., Zhang, B., Yaghi, O. K., and Dai, H. J. (2012). In Vivo fluorescence imaging in the second near-infrared window with long circulating carbon nanotubes capable of ultrahigh tumor uptake. J. Am. Chem. Soc. 134, 10664-10669. doi: 10.1021/ja303737a

Rong, P. F., Yang, K., Srivastan, A., Kiesewetter, D. O., Yue, X. Y., Wang, F., et al. (2014). Photosensitizer loaded nano-graphene for multimodality imaging guided tumor photodynamic therapy. Theranostics 4, 229-239. doi: 10.7150/thno.8070

Rossin, R., Pan, D. P. J., Qi, K., Turner, J. L., Sun, X. K., Wooley, K. L., et al. (2005). $\mathrm{Cu}$-64-labeled folate-conjugated shell cross-linked nanoparticles for tumor imaging and radiotherapy: synthesis, radiolabeling, and biologic evaluation. J. Nucl. Med. 46, 1210-1218.

Ruoslahti, E. (1996). RGD and other recognition sequences for integrins. Annu. Rev. Cell Dev. Biol. 12, 697-715. doi: 10.1146/annurev.cellbio.12.1.697

Sailor, M. J., and Park, J. H. (2012). Hybrid nanoparticles for detection and treatment of cancer. Adv. Mater. 24, 3779-3802. doi: 10.1002/adma.201200653

Sassoon, I., and Blanc, V. (2013). Antibody-drug conjugate (ADC) clinical pipeline: a review. Methods Mol. Biol. 1045, 1-27. doi: 10.1007/978-1-62703-541-5_1

Seynhaeve, A. L. B., Dicheva, B. M., Hoving, S., Koning, G. A., and Ten Hagen, T. L. M. (2013). Intact Doxil is taken up intracellularly and released doxorubicin sequesters in the lysosome: evaluated by in vitro/in vivo live cell imaging. J. Control. Release 172, 330-340. doi: 10.1016/j.jconrel.2013.08.034

Sheldrake, H. M., and Patterson, L. H. (2009). Function and antagonism of beta3 integrins in the development of cancer therapy. Curr. Cancer Drug Targets 9, 519-540. doi: 10.2174/156800909788486713

Shi, S. X., Yang, K., Hong, H., Valdovinos, H. F., Nayak, T. R., Zhang, Y., et al. (2013). Tumor vasculature targeting and imaging in living mice with reduced graphene oxide. Biomaterials 34, 3002-3009. doi: 10.1016/j.biomaterials.2013.01.047

Shiraishi, K., Kawano, K., Minowa, T., Maitani, Y., and Yokoyama, M. (2009). Preparation and in vivo imaging of PEG-poly(L-lysine)-based polymeric micelle MRI contrast agents. J. Control. Release 136, 14-20. doi: 10.1016/j.jconrel.2009.01.010

Sievers, E. L., and Senter, P. D. (2013). Antibody-drug conjugates in cancer therapy. Annu. Rev. Med. 64, 15-29. doi: 10.1146/annurev-med-050311-201823

Silverman, J. A., and Deitcher, S. R. (2013). Marqibo(R) (vincristine sulfate liposome injection) improves the pharmacokinetics and pharmacodynamics of vincristine. Cancer Chemother. Pharmacol. 71, 555-564. doi: 10.1007/s00280012-2042-4

Soundararajan, A., Bao, A., Phillips, W. T., Perez, R., and Goins, B. A. (2009). [Re186]Liposomal doxorubicin (Doxil): in vitro stability, pharmacokinetics, imaging and biodistribution in a head and neck squamous cell carcinoma xenograft model. Nucl. Med. Biol. 36, 515-524. doi: 10.1016/j.nucmedbio.2009.02.004

Sparreboom, A., Scripture, C. D., Trieu, V., Williams, P. J., De, T., Yang, A., et al. (2005). Comparative preclinical and clinical pharmacokinetics of a cremophor-free, nanoparticle albumin-bound paclitaxel (ABI-007) and paclitaxel formulated in Cremophor (Taxol). Clin. Cancer Res. 11, 4136-4143. doi: 10.1158/1078-0432.CCR-04-2291

Steichen, S. D., Caldorera-Moore, M., and Peppas, N. A. (2012). A review of current nanoparticle and targeting moieties for the delivery of cancer therapeutics. Eur. J. Pharm. Sci. 48, 416-427. doi: 10.1016/j.ejps.2012.12.006

Steinmetz, N. F. (2010). Viral nanoparticles as platforms for next-generation therapeutics and imaging devices. Nanomed. Nanotechnol. Biol. Med. 6, 634-641. doi: 10.1016/j.nano.2010.04.005 
Sumitani, S., Oishi, M., and Nagasaki, Y. (2011). Carborane confined nanoparticles for boron neutron capture therapy: improved stability, blood circulation time and tumor accumulation. React. Funct. Polym. 71, 684-693. doi: 10.1016/j.reactfunctpolym.2011.03.010

Sun, X. L., Huang, X. L., Guo, J. X., Zhu, W. L., Ding, Y., Niu, G., et al. (2014). Selfilluminating $\mathrm{Cu}-64$-Doped $\mathrm{CdSe} / \mathrm{ZnS}$ nanocrystals for in vivo tumor Imaging. J. Am. Chem. Soc. 136, 1706-1709. doi: 10.1021/ja410438n

Tang, L., Yang, X. J., Dobrucki, L. W., Chaudhury, I., Yin, Q., Yao, C., et al. (2012). Aptamer-functionalized, ultra-small, monodisperse silica nanoconjugates for targeted dual-modal imaging of lymph nodes with metastatic tumors. Angew. Chem. Int. Ed. Engl. 51, 12721-12726. doi: 10.1002/anie.201205271

Tinkov, S., Winter, G., Coester, C., and Bekeredjian, R. (2010). New doxorubicinloaded phospholipid microbubbles for targeted tumor therapy: part IFormulation development and in-vitro characterization. J. Control. Release 143, 143-150. doi: 10.1016/j.jconrel.2009.12.026

Torchilin, V. (2011). Tumor delivery of macromolecular drugs based on the EPR effect. Adv. Drug Deliv. Rev. 63, 131-135. doi: 10.1016/j.addr.2010. 03.011

Tuerk, C., and Gold, L. (1990). Systematic evolution of ligands by exponential enrichment-RNA ligands to bacteriophage-t4 DNA-polymerase. Science 249, 505-510. doi: 10.1126/science.2200121

Turk, M. J., Waters, D. J., and Low, P. S. (2004). Folate-conjugated liposomes preferentially target macrophages associated with ovarian carcinoma. Cancer Lett. 213, 165-172. doi: 10.1016/j.canlet.2003.12.028

Ujiie, K., Kanayama, N., Asai, K., Kishimoto, M., Ohara, Y., Akashi, Y., et al. (2011). Preparation of highly dispersible and tumor-accumulative, iron oxide nanoparticles Multi-point anchoring of PEG-b-poly(4-vinylbenzylphosphonate) improves performance significantly. Colloids Surf. B Biointerfaces 88, 771-778. doi: 10.1016/j.colsurfb.2011.08.013

Vanblaaderen, A., and Vrij, A. (1992). Synthesis and characterization of colloidal dispersions of fluorescent, monodisperse silica spheres. Langmuir 8, 2921-2931. doi: 10.1021/la00048a013

Verma, S., Miles, D., Gianni, L., Krop, I. E., Welslau, M., Baselga, J., et al. (2012). Trastuzumab emtansine for HER2-positive advanced breast cancer. N. Engl. J. Med. 367, 1783-1791. doi: 10.1056/NEJMoa1209124

Vllasaliu, D., Fowler, R., and Stolnik, S. (2014). PEGylated nanomedicines: recent progress and remaining concerns. Expert Opin. Drug Deliv. 11, 139-154. doi: $10.1517 / 17425247.2014 .866651$

Von Maltzahn, G., Park, J. H., Agrawal, A., Bandaru, N. K., Das, S. K., Sailor, M. J., et al. (2009). Computationally guided photothermal tumor therapy using long-circulating gold nanorod antennas. Cancer Res. 69, 3892-3900. doi: 10.1158/0008-5472.CAN-08-4242

Walkey, C. D., and Chan, W. C. W. (2012). Understanding and controlling the interaction of nanomaterials with proteins in a physiological environment. Chem. Soc. Rev. 41, 2780-2799. doi: 10.1039/clcs15233e

Wang, H. E., Yu, H. M., Lu, Y. C., Heish, N. N., Tseng, Y. L., Huang, K. L., et al. (2006). Internal radiotherapy and dosimetric study for In-111/Lu-177pegylated liposomes conjugates in tumor-bearing mice. Nucl. Instrum. Methods Phys. Res. Sec. A. 569, 533-537. doi: 10.1016/j.nima.2006.08.124

Wang, M., and Gartel, A. L. (2011). Micelle-encapsulated thiostrepton as an effective nanomedicine for inhibiting tumor growth and for suppressing FOXM1 in human xenografts. Mol. Cancer Ther. 10, 2287-2297. doi: 10.1158/15357163.MCT-11-0536

Weissleder, R., Kelly, K., Sun, E. Y., Shtatland, T., and Josephson, L. (2005). Cell-specific targeting of nanoparticles by multivalent attachment of small molecules. Nat. Biotechnol. 23, 1418-1423. doi: 10.1038/nbt1159

Xiao, Y. L., Hong, H., Javadi, A., Engle, J. W., Xu, W. J., Yang, Y. A., et al. (2012). Multifunctional unimolecular micelles for cancer-targeted drug delivery and positron emission tomography imaging. Biomaterials 33, 3071-3082. doi: 10.1016/j.biomaterials.2011.12.030

Yang, K., Hu, L. L., Ma, X. X., Ye, S. Q., Cheng, L., Shi, X. Z., et al. (2012). Multimodal imaging guided photothermal therapy using functionalized graphene nanosheets anchored with magnetic nanoparticles. Adv. Mater. 24, 1868-1872. doi: 10.1002/adma.201104964

Yang, X., Hong, H., Grailer, J. J., Rowland, I. J., Javadi, A., Hurley, S. A., et al. (2011). cRGD-functionalized, DOX-conjugated, and (6)(4)Culabeled superparamagnetic iron oxide nanoparticles for targeted anticancer drug delivery and PET/MR imaging. Biomaterials 32, 4151-4160. doi: 10.1016/j.biomaterials.2011.02.006

Yardley, D. A. (2013). nab-Paclitaxel mechanisms of action and delivery. J. Control. Release 170, 365-372. doi: 10.1016/j.jconrel.2013.05.041

Yokoyama, M., Okano, T., Sakurai, Y., Fukushima, S., Okamoto, K., and Kataoka, K. (1999). Selective delivery of adiramycin to a solid tumor using a polymeric micelle carrier system. J. Drug Target. 7, 171-186. doi: $10.3109 / 10611869909085500$

Younes, A., Bartlett, N. L., Leonard, J. P., Kennedy, D. A., Lynch, C. M., Sievers, E. L., et al. (2010). Brentuximab vedotin (SGN-35) for relapsed CD30positive lymphomas. N. Engl. J. Med. 363, 1812-1821. doi: 10.1056/NEJMoa 1002965

Yu, B., Mao, Y., Bai, L. Y., Herman, S. E., Wang, X., Ramanunni, A., et al. (2013). Targeted nanoparticle delivery overcomes off-target immunostimulatory effects of oligonucleotides and improves therapeutic efficacy in chronic lymphocytic leukemia. Blood 121, 136-147. doi: 10.1182/blood-2012-01407742

Zhan, C., Gu, B., Xie, C., Li, J., Liu, Y., and Lu, W. (2010). Cyclic RGD conjugated poly(ethylene glycol)-co-poly(lactic acid) micelle enhances paclitaxel anti-glioblastoma effect. J. Control. Release 143, 136-142. doi: 10.1016/j.jconrel.2009.12.020

Zhang, R., Lu, W., Wen, X., Huang, M., Zhou, M., Liang, D., et al. (2011a). Annexin A5-conjugated polymeric micelles for dual SPECT and optical detection of apoptosis. J. Nucl. Med. 52, 958-964. doi: 10.2967/jnumed.110.083220

Zhang, R., Xiong, C., Huang, M., Zhou, M., Huang, Q., Wen, X., et al. (2011b). Peptide-conjugated polymeric micellar nanoparticles for Dual SPECT and optical imaging of EphB4 receptors in prostate cancer xenografts. Biomaterials 32, 5872-5879. doi: 10.1016/j.biomaterials.2011.04.070

Zhang, Y., Satterlee, A., and Huang, L. (2012). In vivo gene delivery by nonviral vectors: overcoming hurdles? Mol. Ther.20, 1298-1304. doi: 10.1038/mt.2012.79

Zhao, J., Song, S. L., Zhong, M., and Li, C. (2012). Dual-modal tumor imaging via long-circulating biodegradable core-cross-linked polymeric micelles. ACS Macro Lett. 1, 150-153. doi: 10.1021/mz200034f

Zheng, J., Jaffray, D., and Allien, C. (2009). Quantitative CT imaging of the spatial and temporal distribution of liposomes in a rabbit tumor model. Mol. Pharm. 6, 571-580. doi: 10.1021/mp800234r

Zhu, H., Zhao, J., Lin, X. F., Hong, Y., Li, C., and Yang, Z. (2013). Design, synthesis and evaluation of dual-modality glyco-nanoparticles for tumor imaging. Molecules 18, 6425-6438. doi: 10.3390/molecules 18066425

Conflict of Interest Statement: The authors declare that the research was conducted in the absence of any commercial or financial relationships that could be construed as a potential conflict of interest.

Received: 20 June 2014; paper pending published: 03 July 2014; accepted: 05 August 2014; published online: 25 August 2014.

Citation: Dawidczyk CM, Russell LM and Searson PC (2014) Nanomedicines for cancer therapy: state-of-the-art and limitations to pre-clinical studies that hinder future developments. Front. Chem. 2:69. doi: 10.3389/fchem.2014.00069

This article was submitted to Chemical Engineering, a section of the journal Frontiers in Chemistry.

Copyright (c) 2014 Dawidczyk, Russell and Searson. This is an open-access article distributed under the terms of the Creative Commons Attribution License (CC BY). The use, distribution or reproduction in other forums is permitted, provided the original author(s) or licensor are credited and that the original publication in this journal is cited, in accordance with accepted academic practice. No use, distribution or reproduction is permitted which does not comply with these terms. 